\title{
CONVERSOS I JUEUS: COHESIÓ I SOLIDARITAT. NECESSITAT D'UNA RECERCA
}

\author{
CONVERTED AND JEWS: COHESION AND SOLIDARITY \\ NEED OF AN INVESTIGATION
}

JOSEP HERNANDO

Universitat de Barcelona

Resum: El dia 5 d'agost de 1391 es produïa l'assalt al call major de Barcelona. Immediatament començaren les conversions massives. En aquest article s'exposa la necessitat d'una recerca sobre la població conversa basada en la molt abundosa documentació existent en els arxius barcelonins. Aquesta documentació ens mostra el canvi radical al sí de la comunitat jueva de Barcelona: d'una majoria de jueus a una majoria de conversos. Malgrat tot, es va mantenir la cohesió familiar entre membres jueus i membres conversos. Per altra banda, els Registra ordinatorum conservats a l'Arxiu Diocesà de Barcelona permeten fer-nos la pregunta de si l'accés al clergat per part de conversos és una prova de la sinceritat de llur conversió.

Paraules clau: Jueus; Conversos; Cohesió i solidaritat; Cohesió i família; Conversió $i$ accés al clergat.

\begin{abstract}
The disturbances of 1391 in Barcelona provoked conversions in mass of Jews. In this article there is exposed the need of an investigation based on very abundant documentation preserved in the files. This documentation shows the sudden step of a majority of Jewish population to a majority of converted. Besides this documentation demonstrates the maintenance of the familiar cohesion between jewish members and converted members. The Registra ordinatiorum of the diocesan file of Barcelona allow to raise the question of if the access to the clergy of the converted ones is a test of the sincerity of his conversion.
\end{abstract}

Keywords: Jewish; Converted; Cohesion and Solidarity; Cohesion and family; Conversion and access to the clerical condition.

\section{SUMARI}

1. Introducció.- 2. Cohesió i solidaritat. El testimoni dels processos.- 3. Documentació notarial i altres fonts i els conversos. La necessitat d'una recerca. 4. De la majoria de la població jueva a la majoria dels conversos.- 5 . Conversió i família: cohesió, solidaritat, ruptura.- 6 . L'accés dels conversos a l'estat clerical.- Apèndixs: Apèndix documental.- Apèndix de quadres.Apèndix d'arbres genealògics.

\section{INTRODUCCIÓ}

Hom ha dit que el problema convers constitueix una de les claus fonamentals per a explicar la història peninsular de la Baixa Edat Mitjana i també de l’Êpoca Moderna. El jueu convers, però, és coetani a la polèmica 
Cristianime-Judaisme, és a dir, comença amb l'aparició del Cristianisme en l'escena històrica. A la península ibèrica el convers, quant a problema, cal situar-lo a l'època visigòtica a partir de l'abjuració de l'Arrianisme per Recared, l'any 587, a causa del fanatisme exercit pels nous neòfits, i durant el regnat de Sisebut (612-621) amb les seves lleis antijueves. De l'any 711 al segle XII els jueus fruïren d'una època daurada sota el domini musulmà. L'equilibri i el benestar, però, es trencà amb la invasió dels Almoravits i els Almohades a causa de llur intolerància i fanatisme religiós. No és gens estrany, doncs, que molts jueus emigressin cap els regnes cristians del Nord, on serviren els interessos d'aquests, fruint d'una altra època d'esplendor durant els segles XII i XIII. Simultàniament, però, és a dir, a partir del segle XII, en precisar-se el concepte de Christianitas - lluita de les investidures i progressiu afermament de l'ideal teocràtic, croades i concreció de la Guerra Santa- es comença a produir un canvi en l'actitud dels cristians envers els jueus en tots els ordres. Es produí, per tant, de manera progressiva un canvi profund en la condició del poble jueu: hom anà passant d'una autonomia limitada a una condició d'absoluta subjecció i d'inferioritat davant els cristians. Si bé és cert que no en tots els Estats les noves condicions s'imposaren al poble hebreu amb el mateix rigor, sí que ho és que a la fi del segle XIV la posició dels jueus en tots els estats europeus era insostenible.

Aquesta hostilitat tingué com a conseqüència els primers disturbis o "progroms" que començaren a Sevilla el març de 1391, seguiren per tota Andalusia i ambdues Castelles i arribaren a Aragó mitjan l'any. La conseqüència fou tot un seguit de conversions en massa, en optar pel baptisme i no pel martiri voluntari com a Anglaterra i Alemanya. Moltes aljames es dispersaren i, fins i tot, desaparegueren. Les predicacions de Sant Vicent Ferrer $^{1}$ i la Disputa de Tortosa ${ }^{2}$ feren la resta. La conseqüència va ser la formació d'una minoria o classe social que per antonomàsia hom anomenarà dels conversos i que afecta de manera exclusiva als que procedien del judaisme. Es tracta d'un procés que comença el segle XIV i s'accelera fins l'expulsió d'any $1492^{3}$.

${ }^{1} \mathrm{~F}$. VENDRELl GALlOSTRA, La actividad proselitista de San Vicente Ferrer durante el reinado de Fernando I de Aragón, «Sefarad», XIII (1953), pp. 87-104.

${ }^{2}$ A. Pacios LóPEZ, La disputa de Tortosa (2 vols.), CSIC, Madrid, 1957.

${ }^{3} \mathrm{~J}$. AMADOR DE LOS RíOS, Historia de los judios (3 vols.), Ed. Turner, Madrid 1984 (1 a ed. 1875); YY. BAER, Historia de los judíos en la España cristiana (2 vols.), Altalena Ed. Madrid General de Aragón, Zaragoza 1985 (1 a ed de 1913); A. MALAMAT - H. TADMOR - M. STERN H. SAFRAI - H. BEN-SASSON - E. ETTINGER, Historia del pueblo judio. 2 Edad Media Alianza H. SAFRAI-H. BEN-SASSON - E. ETTINGER, Historia del pueblo judio 2 Edad Media, Alianza Ed., Madrid 1988; L. POLIAKOV Historia del Antisemitismo. I De Cristo a los judios de las Cortes, Muchnik Ed. Barcelona $1986\left(1^{\mathrm{a}}\right.$ ed. de 1955); A. RICH ABAD, La comunitat jueva de Barcelona entre 1348 i 1391 a traves de la documentació notarial, Fundació Noguera Barcelona 1999; L. SUÁREZ FERNÁNDEZ, Judíos españoles en la Edad Media, Ed. Rialp, Madrid 1980; L. SUÁREZ FERNÁNDEZ, Los judíos, Ed. Ariel, Barcelona 2003. Sobre els jueus a Catalunya, vegeu el treball breu, però destacable, J. RIERA SANS, La Catalunya jueva del segle XIV, «L Avenç» 25 (1989), pp. 52-55. I sobre Barcelona del mateix autor Els jueus a Barcelona entre els segles XII $i$ XIV, dins Catalunya Romànica, vol. XX, Barcelona, Enciclopèdia Catalana, 1992 , pp. 88-91. 
A causa d'aquestes conversions en massa, hom veia, dins la comunitat cristiana, que a més de tenir una homogènia minoria jueva, ara hi havia una gran nombre de cristians nominals dispersos arreu i que no tenien quasi cap mena de restricció per a exercir la majoria de professions dels cristians de natura. Les relacions amb els neòfits no foren massa bones dins aquesta societat, car tant els conversos forçats com els de bon grat seguiren vivint, no tots, ben cert, de manera agrupada i exerciren les mateixes activitats professionals que quan eren jueus. És per això que, com hom ha dit, estaven condemnats a viure en una «societat transitòria» al marge de les dues religions. Si la conversió, en un principi, els hauria hagut d'obrir les portes de la societat, el cert és que transformà l'odi envers els jueus en l'odi envers els conversos, perquè «lo juheu convers o batejat fou sempre mal mirat pel poble». Per la seva nova condició, el convers era apte per a ésser subjecte de tots els drets polítics del ciutadà, però ensems tenia relacions tenses amb els ciutadans cristians "de natura" per la sospita, real o no, de la minsa sinceritat de les conversions i perquè no se'ls conceptuava com de la mateixa raça ${ }^{4}$.

Dins les comunitats jueves, la conseqüència més important fou, com ja s'ha dit, la decadència, i també en molts casos la desaparició, de les aljames, tant en els seus membres com en les riqueses. Tanmateix, les relacions amb els neòfits cristians, els conversos, eren bones i hom els ajudava amb tots els mitjans a l'abast. Els jueus pensaven que un jueu, malgrat pecador, és a dir, convers, segueix sent jueu, per la qual cosa el convers que tornava al judaisme era rebut de bon grat. Actitud ben diferent a la dels cristians.

¿Conversions sinceres? ¿Mitjà per a salvar la pròpia vida? Hom no dubta de la conversió de molts, però la historiografia sobre els conversos ${ }^{5}$ porta a fer pensar que la majoria dels conversos ho eren perquè no hi havia altre remei, com es pot deduir, entre d'altres fets, de les conversions massives produïdes l'endemà mateix de l'assalt al call de Barcelona el dia 5 d'agost de 1391, com veurem més endavant. Eren jueus, com hom ha dit, en tot menys en el nom i cristians en res menys en la forma. Si aixó és així, res d'estrany que molts conversos no respectessin les normes cristianes i seguissin molts dels preceptes jueus, entre els quals sempre fou predominant la pràctica de la circumcisió, com veurem més endavant ${ }^{\circ}$.

${ }^{4}$ Vegeu l'excel-lent treball J. RIERA SANS, Judíos y conversos en los reinos de la Corona de Aragón durante el siglo XV. dins La expulsión de los judios de España Conferencias pronunciadas en el II Curso de Cultura Hispano-Judía y Sefardí de la Universidad de Castilla-La Mancha, 1992, pp. 71-90. Hom no pot oblidar el treball encara molt útil F. CARRERAS CANDI Evolución histórica de juehus y juheissants barcelonins eEstudis Universitaris Catalans", III (1909), pp. 404-428 i 498-522; IV (1910), pp. 45-65 i 359-373.

${ }^{5}$ E. BENITO RUANO, Los orígenes del problema converso, Barcelona, Ed. El Albir, 1976; C. Roth, Los judios secretos. Historia de los marranos, Madrid, Ed. Altalena, 1979.

${ }^{6} \mathrm{La}$ por d'algunes llevadores d'infants i alguns pares de nadons de ser acusats d'haver practicat, o permès practicar, la circumcisió és l'objecte de diversos instruments notarials a partir

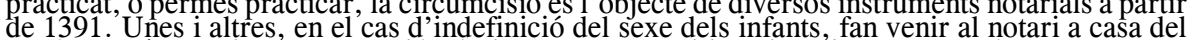
nadó perquè consti llur declaració pública davant notari i testimonis que el nadó, nascut suara, és "nat circumcís". Aquest és el cas d'una llevadora d'infants segons document datat el dia 26 de juliọl de 1415: "Noverint universi quod die veneris, XXVI die rulii, anno predicto, circa horam terciam post prandium, in presentia Iohannis Pedrolo, scriptoris iurati sub me Iacobo de Trilea, 


\section{COHESIÓ I SOLIDARITAT. EL TESTIMONI DELS PROCESSOS}

Malgrat que no és molta la documentació conservada procedent dels processos per aquells delictes que eren de jurisdicció de l'Inquisitor Hereticae pravitatis, delegat especialment per la Seu Apostòlica, abans de que hom establís la Inquisició castellana l'any 1487, els protocols notarials medievals, en els seus llibres o capbreus, contenen en forma pública algunes de les actuacions dels inquisidors $i$, en alguns casos, el resultat en sentència dels processos per crim d'heretgia, que tot seguit eren lliurades als interessats per a poder fer valer, davant uns $i$ altres, la sentència absolutòria o la sentència amb la pena imposada.

Si tenim present que la presència del notari era indispensable en el cas dels processos i també en aquells que generà l'actuació del Sant Ofici de la Inquisició (Sanctum Officium Inquisitionis Haereticae Pravitatis), res d'estrany, doncs, el fet de l'existència de documentació relacionada amb la

auctoritate regia notario publico Barchinone infrascripto, et in presentia etiam discreti Berengarii Gencana, presbiteri, et Petri Ocello, payerii, civis Barchinone, testium ad hec vocatorum et assumptorum, quedam domina madrina sive levadora de infans, tenens in sua fimbra sive falda quendam puerum, filium Iacobi Taladell, sartoris, et domine Blanquine, eius uxoris, et dixit hec verba in effectu: Senyors, à ací aquest infant, lo qual és nat suara, és nat circumcís, segons quescú de vosaltres a huy podets veura. E jo noll'é volgut bolcar ni metra en lit en tro ho haguessen vist persones de bona fe. Et quibus sic dictis, dictus Iacobus Talladell verbo petiit et requisivit de predictis sic dictis et gestis fieri publicum instrumentum", AHPB, Jaume de Trilla Manual 1415-1416, fọ. 43r. També és el cas de Gaspar Mir, pare d'ụn nadó, que fa declaracio publica davant notari i testimonis l'any 1478: "Noverint universi quod die vẹneris, qua computabatur tricesima mensis ianuarii, anno a nativitate Domini millesimo septuagesimo octavo, vocato me Iacobo Mas, auctoritate regia notario publico Barchinone infrascripto, una cum testibus infrascriptis, per Gasparem Mir, payerium, civem Barchinone, comorantem in vico vulgariter dicto del Calt olim iudayco Barchinone, quod est in parrochia Sancti Iacobi dicte civitatis, in quadam camera domus sue existentem una cum domina Beneta, uxore sua, in quodam transponte iacente cum uno infante masculo, de proxime nato ab eadem, et una cum domina Blanquina uxore Ferrarii Vilanova, quondam, civis Barchinone, matrona sive levadora dicti infantis, et aliquibus mulieribus ibidem existentibus, idem Gaspar Mir dixit hech verba, ea dirigendo michi, dicto notario: Sènyer, jo us requir: mireu e regonegau aquest infant, fill meu e de madona Beneta, muller mia, que aci jau ab aquell, lo qual és nat circuncís, e del que veureu me doneu acta públich, a ffi que tal acta puxe ésser en qualsevulla part e devant qualsevulla officials testiffica $e$ ab aquetl verifficat. Et continuo facta dicta requisitione, ego dictus Iacobus Mas una cum testibus infrascriptis et etiam mulieribus ibidem existentibus vidimus dictum infantem de proximo, ut aperabatur natum ibidem, nudum iacentem inter tibias dicte domine Benete, matris sue, cuius lombricum sive lombrigo nondum a dicta levadora erat scizum et sine aliqua lesione membri dict infantis fuit visum circumcizum, scilicet sine pello in capite membri eiusdem ita quod videbatur infan ip fum infantem circumeizum, scilicet sine pello in capitu sich ipsum infantem circumcisum fore natum. Et hech testifficavit medio iuramento dicta domina Blanquina, matrona sive levadora dicti infantis. Et hech eadem fuerunt visa per Bartholomeum Foguet, tornerium, et Andream Amorós, payerium, cives Barchinone, qui pariter dixerunt, attenta nascione nova dicti infantis et in eo seu elus membro nullam aparere lesionem, quod ipse infans, sich ut fuit visus, circuncisus est natus. De quibus omnibus et singulis ita visis, dictis et testifficatis, idem Gaspar Mir verbo petiit et requisivit sibi fieri et tradi unum et plura publicum et publica instrumenta per me dictum et infrascriptum notarium. Que fuerunt acta Barchinone, die, anno, mense, loco et forma premissis, presente me dicto et infascripto notario et presentibus etiam dictis Bartholomeo Foguet, tornerio, et Andrea Amorós, payerio, civibus Barchinone, pro testibus ad hech vocatis specialiter et assumptis, ut superius continetur", AHPB, Jaume Mas, Manual

7 "Habeat ergo notarios publicos Episcoporum, locorum vel dominorum temporalium illarum terrarum vel regnorum, in quibus officium est sibi commissum, qui processus conficiant et alia quae ad negotia fidei pertinent, exequantur", N. EIMERIC, Directorium inquisitorum, Romae, 1585 , pp. 592-93. 
Inquisició que hom pot trobar en els protocols notarials: actes dels processos contra acusats d'heretgia, actes de les apel-lacions presentades pels acusats, nomenaments de procuradors per part dels acusats, etc. Documentació, per altra banda, que no ha cridat, fins ara, l'atenció dels historiadors ${ }^{8}$.

Aquest és el cas de l'instrument notarial, datat el dia 30 de desembre de 1417, de l'acta pública de les actuacions de l'Inquisidor Francesc Sala, de l'orde dels Predicadors', contra Na Yoya Ermengola, conversa, vídua de Joan Ermengol, sastre, ciutadà de Barcelona, acusada de pràctiques judaiques (Vegeu Apèndix Documental, doc. 9). Aquest instrument públic va ser validat per Pere de Puig, notari públic de la ciutat de Barcelona ${ }^{10}$ i també notari del tribunal del Sant Ofici de la Inquisició. Na Yoya havia viatjat a casa dels seus parents ("inducta et seducta in gradu parentele et aliorum») a Cervera, Tarragona, Sant Vicenç dels Horts. Amb ells havia observat les festivitats judaiques ("in festivitatibus precipuis iudeorum fuit frequentissime conversata": Yom Quipur o Dia del Perdó, Pesaj o Pascua, Purim, Sucot o festa dels Tabernacles, Shavuot o Pentacosta, etc.). En aquestes visites complia les prescripcions referents als aliments, és a dir, observava la "cashrut" o adequació ritual amb la llei jueva dels aliments, tot recitant les plegàries o benediccions o "berajot", que hom podia trobar en el "sidur" o llibre de pregàries, menjava el pa sense llevat o àzim o "matzà" en la festa de Pasqua ("cibariaque iudeorum cum eorum serimoniis preparata necnon panes azimos in festivitatibus ipsorum paschalibus comedit), visitava i entrava en les sinagogues ("eorumque sinagogas intravit et frequenter etiarn visitavit"), etc. Per tot això, en demostrar rebuig a la fe cristiana, va incórrer en excomunió major $^{11}$, d'acord amb el que establia el Dret Canònic ${ }^{12}$, és a dir, la privació activa i passiva dels sagraments i sufragis comuns dels fidels ("ipsam absolvimus a maioris excomunicationis sententia qua incurrerat"). En el procés endegat contra ella ("prout hec onmia et alia in processu inde coram nobis actitato plenius et extensius continetur"), en mostrar arrepentiment, malgrat la culpabilitat, hom la va absoldre de la sentència d'excomunió major

${ }^{8}$ Bartomeu Costa (major), notari públic de la ciutat de Barcelona, actuant entre els anys 1438 i 1498, va ser un dels notaris del tribunal del Sant Ofici de la Inquisició durant diversos anys a la ciutat de Barcelona. Es per això que els intruments notarials dels seus protocols que fan referència a processos inquisitorials per açusacions d'heretgia són nombrosos. Vegéu J. HERNANDO DELGADO Processos inquisitorials per crim d’heretgia $i$ una apel lació per maltractament i parcialitat per part de l'Inquisidor (1440). Documents dels protocols notarials, «Estudis Històrics i Documents dels Arxius de Protocols», XXIII (Barcelona, 2005), pp. 75-139.

${ }^{9}$ Francesc Sala començà a exercir la tasca d'Inquisidor General a la Corona d'Aragó l'any 1408 i encara ho era l'any 1440 . Vegeu J. HERNANDO I DELGADO, Processos inquisitorials per crim d'heretgia, cit., p. $93 \mathrm{i}$ ss. Vegeu també A. ESPONERA CERDÁ, Los dominicos y la crim d'heretgia, cit., p. 93 i ss. Vegeu també A. ESPONERA CERDÁN, Los dominicos y la
Inquisición medieval según la Historia de la Santa Inquisición (1589-92) de V. J. Antist OP, dins Inquisicion medieval según la Historia de la Santa Inquisicion (1589-92) de V. J. Antist OP, dins
Praedicatores, Inquisitores. I De Dominicans and the Medieval Inquisition, Actes of the $1^{\mathrm{st}}$ Praedicatores, Inquisitores. I De Dominicans and the Medieval Inquisition, Actes of the $1^{\text {st }}$
International Seminar on the Dominicans and the Inquisition, Rome, 23-25 February, 2002, Istituto Storico Dominicano, Roma, 2004, p. 751.

${ }^{10}$ Pere de Puig actuà com a notari públic de Barcelona, almenys, entre els anys 1417 i 1455. Vegeu LL. CASES I LOSCOS, Inventari de l'Arxiu Històric de Protocols de Barcelona, I Segles

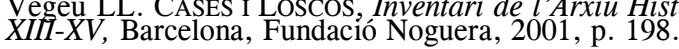

${ }^{11}$ Vegeu l'article Excommunication, dins Dictionaire de Droit Catholique, t. V, Paris 1953, cols. 615-616.

${ }^{12}$ Decretales Gregorii IX, L. V, T. XXXIX, c. 49, (Ed. E. FrIEDBERG, Leipzig, II, col. 910). 
i li va ser imposada una penitència ("pro comissis eam sententialiter condempnando penitentiam iniunximus salutarem"), que podem suposar lleu, si tenim present el to del document i altra praxis de la Inquisició Medieval a Catalunya en aquest segle XV abans de l'arribada de la Inquisició "castellana". Aquest document públic lliurat a l'acusada havia de servir davant qualsevol autoritat o persona en el cas de malfiança o temptació de nova acusació. [Apèndix Documental, doc. 9].

El procés número 762 de l'Arxiu Diocesà de Barcelona, que porta el títol Processus inquisitionis facte contra Sanxo, civem Barchinone, confirma tot el que s'ha dit ${ }^{13}$. El dia 22 de desembre de 1437, l'esposa del convers Nicolau Sanxo, fill del també convers Guillem Sanxo, paria un infant. Un error de la llevadora d'infants, també conversa, Salvadora, vídua del també convers Guerau Sust, que afirmà que era una nena, féu que el nadó fos batejat amb el nom d'Eulàlia. Poc després, en comprovar que no era una nena sinó un nen, el nadó va ser de nou batejat "sub conditione" amb el nom de Nicolau. De tot això, el resultat va ser que s'iniciés un procés contra Nicolau Sanxo per criptojudaisme. A més a més dels efectes negatius amb conseqüències possibles en tots els aspectes de la vida d'aquella família de conversos, el procés mostra, quasi mig segle després del progrom de 1391, la cohesió del grup dels conversos en la convivència, els matrimonis, el treball, etc. Guillem Sanxo, l'avi del nadó, estava maridat amb Eulàlia, filla del mestre en medecina i convers Francesc de Pedralbes, que tenia 8 fills vius en fer testament l'any 1425: Eulàlia, Joan, Francesc, mestre en medicina i metge que tingué cura del nadó, Nicolau, Violant, Constança, Isabel i una altra filla de la qual no sabem el nom. L'avi del nadó, Guillem, maridat amb Eulàlia, filla de Francesc de Pedralbes, com hem dit, tingué 3 germans documentats: Domènec, Francesc i Joan. Violant, filla del dit Francesc de Pedralbes, esposà el convers Joan de Ravat. Isabel, filla també de Francesc de Pedralbes, estava unida en matrimoni amb el convers Llorenç Massana, fill d'Antoni Massana, i germà d'Arnau, Joan, Daniel i Nicolau. Per tant, l'entorn familiar dels Sanxo era, com a mínim, els Pedralbes, els Massana, els Ravat. En el procés, endemés, són citades persones d'altres famílies de conversos: els Canal, els Gualbes, els Cortey. Res d'estrany, doncs, que l'entorn convivencial de la família dels conversos Sanxo fos quasi totalment convers, cosa que mostra el procés, com es pot veure en els arbres genealògics que reproduïm amb les dades del procés i les dades de la documentació notarial consultada. Això explica, per altra banda, la presència de diverses persones, a vegades moltes, citades anònimament: "E la dita madrina e lo pare e les altres dones... Francesc de Pedralbes ab VII o VIII d'altres... en Ramon Canal e mestra Francesch de Pedralbes e molts d'altres... Francesc de Pedralbes e altres persones, hòmens e donas... E de fet... el dit mestra Francesch e lo dit Loys

${ }^{13}$ J. HERNANDO i A. IBÀÑEZ, El procés contra el convers Nicolau Sanxo, ciutadà de Barcelona, acusat d'haver circumcidat el seu fill (1437-1438). Processus inquistionis facte contra Sanxo, conversum, civem Barchinone, «Acta Historica et Archaeologica Mediaevalia», 13 (1992), pp. 75-100. 
Vives, ab altres qui·lls acompanyaren... presents... madona d'en Manuel de Gualbes e d'altres hòmens e dones, a sos viares conversos... informada per la mare e per altres dones ... ella testimoni [la llevadora] ab dues altres dones e ab lo pare de la creatura... ella [la llevadora]... ne IIII $^{\mathrm{e}}$ o $\mathrm{V}$ dones que ho veheren...". (Vegeu l'Apèndix d'Arbres Genealògics:10. Els Sanxo, els Pedralbes, els Massana, els Ravat).

\section{DOCUMENTACIÓ NOTARIAL I ALTRES FONTS I ELS CONVERSOS. LA NECESSITAT D'UNA RECERCA}

Com sabem, el dia 5 d'agost de 1391 es produïa l'assalt al call major de Barcelona. Foren assassinats centenars de jueus, el call fou saquejat i hom cremà l'arxiu notarial. Immediatament començaren les conversions massives de jueus ${ }^{14}$. Les fonts notarials proporcionen abundosa informació sobre la vida interna de la comunitat jueva i conversa. Hom pot veure els individus dins el col-lectiu jueu i convers: llocs de residència, formes de vida, ocupacions professionals, posició dins el mercat monetari, per tant les possibilitats econòmiques, les relacions dins un entorn professional, els lligams familiars, els vincles socials. Jueus i conversos vivien immersos en la realitat cristiana, parlaven català, empraven el llatí, feien ús de formes econòmiques cristianes $\mathrm{i}$ les reflectien davant notaris cristians. És a dir, els aspectes que es desprenen de la documentació notarial són la vida del conjunt jueu o convers, la seva dimensió física, les tendències socials i les estructures jeràrquiques, la seva ubicació en la ciutat de Barcelona, el lloguer, compra i venda de cases, l'estructura socioeconòmica, el comerç i finances, l'establiment d'aliances entre les famílies, la consciència de grup i d'exclusivitat, l'exercici d'uns oficis determinats ${ }^{15}$, etc. Som conscients de la complexitat de la societat jueva conversa i les seves relacions amb l'entorn dels cristians de natura i que les dades que contenen els protocols notarials s'han de confrontar amb altra tipologia de fonts. Caldria fer, doncs, un buidat sistemàtic dels protocols notarials i també d'altres fonts. Proposem tres exemples que ens mostrarà la necessitat d'aquesta recerca. En el primer, el buidat d'un protocol ens demostrarà el canvi radical en la comunitat jueva de la ciutat de Barcelona tot seguit dels fets del dia 5 d'agost de 1391. En el segon, fruit del buidat dels protocols posteriors a la data esmentada, veurem la cohesió de les famílies amb membres jueus i conversos. En el tercer, proposem la hipòtesi, sempre revisable, de la integració del conversos en la societat dels cristians de natura

\footnotetext{
14“E lo dia de dimarts següent (= 8 d'agost de 1391) tots los juheus qui eren en lo dit castell e la maior partida se faeren christians, sino forsa CCC quin moriren", diu l'anotació feta en el dietari del Concell Municipal de Barcelona. Vegeu F. SCHWARTZ Y LUNA - F. CARRERAS CAND (eds.), Manual de novells ardits, Barcelona, 1892-1894, vol. I, p. 18.

${ }^{15}$ Aquest és el cas de l'ofici de llibreter quasi monopolitzat per llinatges de conversos: els Bertran, els Sa Coma, els Bosc, els Cardona, els Sa Conomina, els Des Feu, els Mascaró, els Ramon, els Cortey, els Trinxer, els Roger, els Sastre. Vegeu J. HERNANDO I DELGADO, Del llibre manuscrit al llibre imprès. La confecció del llibre a Barcelona el segle XV. Documentació notarial, «Arxiu de Textos Catalans Antics», 21 (2002), pp. 270-271.
} 
fent ús dels registres dels qui rebien ordes sagrades per tal de veure l'accés dels conversos a l'orde clerical.

\section{DE LA MAJORIA DE LA POBLACIÓ JUEVA A LA MAJORIA DELS CONVERSOS}

Si abans del progrom iniciat el dia 5 d'agost de 1391 a Barcelona les conversions de jueus al cristianisme eren casos aillats i esporàdics, a partir d'aquest dia la situació canvià de manera radical. Alguns jueus foren morts, altres fugiren i pocs seguiren fidels a la seva fe. La majoria, però, es convertia a la fe cristiana i canviaren el nom jueu per un de cristià. El notari Jaume de Trilla en el protocol que conté els instruments notarials relatius als anys 1391 i 1392 ens ha deixat una mostra del que passà, és a dir, la conversió al cristianisme quasi espontània de molts jueus, a partir del dia 5 d'agost de 1391. La majoria dels instruments notarials d'aquest protocol, fins la data de l'assalt al call jueu [és a dir, el dia 5 d'agost de 1391] fan referència a jueus de Barcelona, amb una excepció: la de Francesc Casasaja, dit Bonjach Comprat abans de la seva conversió. A partir d'aquesta data [el primer contracte és del dia 22 d'agost de 1391] la majoria dels contractes fan referència a conversos. Hem fet el buidat dels instruments relatius a jueus $\mathrm{i}$ conversos de tot el protocol i el resultat és el que es pot veure en el quadre que es troba a l'Apèndix de Quadres: 1. Jaume de Trilla, Undecimum manuale, advertint que transcrivim els noms jueus tal com es troben en el protocol $^{16}$.

El call va ser destruït. La població jueva, ara conversa, es va traslladar a altres llocs de la ciutat. Un grup nombrós el trobem en els carrers Regomir i Gignàs o Guimnàs, molt propers al call destruït. Un altre grup és localitzat prop de l'església de Santa Maria del Mar. Altres canviaren de població, passant a viure a Santa Maria de Sants, Sant Andreu de Palomar, Molins de Rei. Convers vol dir ser cristià. Es per això que també calgué trobar un espai nou per als difunts. Els testaments de conversos ens mostren la preferència d'aquests pel cementiri de l'església de Santa Maria de Natzaret. La vida personal, familiar i professional dels conversos seguí després del desastre de l'any 1391. Els conversos de la ciutat de Barcelona es relacionaren, sobretot, amb altres conversos. Però també amb els jueus que seguiren vivint a Barcelona. I també amb jueus i conversos d'altres indrets de Catalunya: per exemple, Agramunt, Castelló de Farfanya, Falset, Figueres, Girona, Montblanc, Puigcerdà, Sant Vicenç de Cervelló, Solsona, Tàrrega, Tortosa, etc. I també del regne de València, del regne d'Aragó, de Sicília, de França. I això perquè si la conversió va ser massiva, a Barcelona almenys, no

\footnotetext{
${ }^{16}$ Vegeu també I. LOEB, Liste nominative des juifs de Barcelone en 1392, «Revue des Études Juives», IV (1888), pp. 55-77, en què es reprodueix, en part, el text d’Andreu Balaguer y Merino publicat a Veu de Catalunya dẹ l'any 1881, que conté un llistat de conversos nomenant publicat a Veu de Catalunya de l'any 1881, que conte un llistat de conversos nomenanants procuradors perquè els fos 5 d'agost de 1391 .
} 
va ser tota ${ }^{17}$. Tanmateix, a mida que ens acostem a la fi del segle, la presència de jueus en la societat barcelonina va minvant, fet que s'anirà accentuant fins arribar a la sortida de l'any $1492^{18}$

\section{CONVERSIÓ I FAMÍLIA: COHESIÓ, SOLIDARITAT, RUPTURA}

Les conversions foren "massives", tanmateix no foren totals. Més encara, les conversions no foren homogènies al si de les famílies. Uns membres es convertiren, altres no. En el cas de compromís matrimonial, hom pot observar que la conversió d'un dels membres és, potser, de conveniència, és a dir, perquè l'altre ja és convers. Per altra part, hom pot observar que la conversió del marit i la fidelitat a la fe jueva de la muller, tingué com a conseqüència el trencament del matrimoni i la devolució del dot. Tanmateix, aquesta divergència de fe entre els membres d'una família no comportà necessàriament el trencament dels vincles familiars. Més aviat podria respondre la conversió d'un del membres a raons d'estratègia, és a dir, per a accedir més fàcilment a certs llocs, institucions i persones. Hom pot veure tot seguit aquesta divergència de fe al si de les famílies.

El mateix any de l'assalt al call, és a dir, l'any 1391, el mes de desembre, Ferrer de Gualbes, convers, de nom Issac Bonsenyor de Gualbes quan era jueu, actua com a procurador del seu pare encara jueu, Bonsenyor Gracià, i del seu germà també jueu, Mosse Bonsenyor Gracià, en el cobrament de certes quantitats degudes per cristians de natura als seus pare $\mathrm{i}$ germà jueus. (Vegeu: Apèndix Documental, doc. 1; Apèndix d'Arbres Genealògics, 1. Família de Bonsenyor Gracià).

Si en el cas propdit el pare és jueu i també un dels fills, mentre l'altre fill ja és convers, en el cas que segueix, datat el 28 de febrer de 1392, Lleonard Ferrer, convers, dit Bonjuha Bonsenyor quan era jueu, pare, i Vidal Bonjuha, jueu, fill, en haver promès pagar a Dolça, conversa, dita Vidala

\footnotetext{
${ }^{17} \mathrm{El}$ buidat dels protocols corresponents als anys 1391, aquest a partir dels fets del mes d'agost, 1392 i 1393 permet constatar la presència i activitat de jueus a Barcelona, malgrat la conversió d'una gran part d'ells. Escrivim tot seguit alguns de llurs noms: Abraham Benvenist, conversio Arraham Hahanel, Abraham Issach Benvenist, Abram Cabatay, Asday Brunell, Asday Cresques, Astruch Bondavi des Cortal, fill, Astruch ça Porta, Astruch Jucef Levi, Astruch Juceff, Astruch sa Porta, Aterita, Benvenist Samuel, Blanca, Bonaffia, Bonafós Ali, Bondavi des Cortal, Bonjuha Barzelay, Bonjuha Juceff, Bonjuha Salom, Bonsenyor Gracià, Cimata, Clarià Içach, Cresques Salamó, Davi Aron, Davi Corayeff, Davi Fabib, Ducinella, Durona, Ferrer Benvenist, Frescha, Fudano Galluf, Issach Gracià Jacob de Corsi, Juceff Abenaffia, Juceff Mosse, Leo Cavernet, Manahem Salamó, Maymó Vidal, Mose Bonsenyor Gracià, Mosse Abraham, Mosse Bonsenyor Gracià, Mosse de Piera, Nathan Abram, Salamó Cresques, Salamó Gracià, Salomó Gracià, Salomó Nassim, Saltell Cabrit, Saltell Gracià, Samuel Benvenist, Samuel Bonjam, Samue de Tolosa, Samuel Gracià, Samuel sa Porta, Saricha, Struch Cresques, Struch Bondavi des Cortal, Vidal Benvenist, Vidal Bonjuha, Vidal de Ripoll, Vidala, etc.

${ }^{18}$ Jaume Riera afirma sobre la població conversa i jueva de Catalunya que "en total, sumats els uns i els altres, a tot Catalunya, poc més de 10.000 jueus, 12.000 a tot estirar, comptats homes, dones i infants, a cada generació del segle XIV.... Però el cạs és que quan Ferran II en va decretar l'expulsió, més de les dues terceres parts dels jueus existents a Catalunya al segle anterior ja s'havien convertit i eren considerats legalment cristians. Els jueus que sortiren de Catalunya l'any 1492 (i del Rosselló el 1493), doncs, no eren més de 3.000”. Vegeu J. RIERA I SANS, La Catalunya jueva del segle XIV, cit., p. 55 [207].
} 
quan era jueva, muller de David Aron, jueu, 15 lliures, i en haver cedit Dolça el seu dret contra pare i fill a Francesc Burgués, convers, dit Vidal Alcacauny quan era jueu, sobre 14 lliures i 9 sous, el pare, jueu, i el fill, convers, paguen les 14 lliures i 9 sous $^{19}$. (Vegeu: Apèndix Documental, doc. 3; Apèndix d'Arbres Genealògics, 2. Família de Bonjuha Bonsenyor).

En el cas que segueix el convertit és el fill d'un jueu i nebot del germà d'aquest, també jueu, el conegut Samuel Benvenist. És a dir, l'any 1392, el dia 16 del mes d'octubre, Joan Bertran, convers, dit Samuel Benvenist quan era jueu, fill del jueu Ferrer Benvenist, i el seu oncle Samuel Benvenist, jueu, venen una casa a Esteve sa Torre, apotecari, ciutadà de Barcelona i reben 4.400 sous, que són part del preu de la casa. (Vegeu: Apèndix Documental, doc. 5; Apèndix d'Arbres Genealògics, 3. Família de Benvenist Samuel).

Un any i mig més tard, és a dir, l'any 1394, els germans Pere Benet de Rexach, convers, habitant de Barcelona, dit Benet Belshom quan era jueu, i Mosse Belshom, jueu, ambdós de Girona, hereus universals a parts iguals de llur pare i germà, difunts, ambdós dits Vidal Belshom, ratificaren i confirmaren la venda d'una casa que havia fet Samuel Benvenist, jueu de Barcelona, a Pere Pascasi, doctor en ambdós drets, ciutadà de Barcelona. En aquest cas, també, un dels fills és convers. (Vegeu: Apèndix Documental, doc. 6; Apèndix d'Arbres Genealògics, 4. Família de Vidal Belshom).

¿Conversions per conveniència en cas de matrimoni $\mathrm{o}$, com hem dit, per raons d'estratègia? Aquest sembla ser el cas que segueix on es mostra la solidesa dels lligams familiars malgrat la conversió al cristianisme d'un dels membres jueu. En instrument datat el dia 30 de gener de 1404, Vidal de Beses, jueu de Solsona, fill de Juceff de Beses, també jueu de Solsona, promet al seu germà Joan de Cardona, convers, mercader de Barcelona, que per raó del matrimoni entre Joan de Cardona i Elionor, filla de Berenguer de Cortil, convers, mercader, ciutadà de Barcelona, i per amor fraternal, que durant tres anys, a partir de la propvinent festa de Pasqua, proveirà els dits cònjuges $\mathrm{i}$ llurs fills en aliments d'acord amb la seva condició social. Joan Cardona, ja domiciliat a Barcelona, serà el representat o procurador del seu pare en diverses operacions comercials ${ }^{20}$. (Vegeu: Apèndix Documental, doc. 7; Apèndix d'Arbres Genealògics, 5. Família de Juceff de Beses i Berenguer de Cortil).

\footnotetext{
${ }^{19}$ Són molts els instruments notarials en què hom pot veure la convivència dins la família de conversos i jueus. Per exemple, poc més d'un mes després de l'asalt al call de Barcelona, el dia 11 de setembre de 1391 , en una àpoca d'un dot de 16 lliures i 3 sous trobem que l'esposa és Joaneta, conversa, dita Douda quan era jueva, filla de Jaffudam Cathan, jueu de Barcelona, de Bonafia, jueva de Barcelona. L'espòs era Pere Taverner, convers, ciutadà de Barcelona, di Vidal Rovén quan era jueu, fill de Rovén Levi, tintorer, jueu de Barcelona. Vegeu AHPB, Bernat Nadal, Manual 1391, juny, 7 - 1392, gener, 2, fol. $51 \mathrm{v}$.

${ }^{20}$ Per exemple, aquest és el cas de l'instrument datat el dia 14 de maig de 1406: "Iohannes de Cardona, conversus, mercator Barchinone, procurator ad hec et alia specialiter constitutus a
Iuceffo de Beses, iudeo, habitatore ville Celsone, patre meo, prout ... confiteor et recognosco luceffo de Beses, iudeo, habitatore ville Celsone, patre meo, prout ... confiteor et recognosco vobis venerabili Michaeli Franch, mercatori, civi Barchinone, quod super illa comanda trecentarum decem librarum, duodecim solidorum et undecim denariorum, quas vos et Petrus
Seragoca, patronus navis, civis Barchinone, confessi fuistis habuisse et recepisse et portare in Seragoça, patronus navis, civis Barchinone, confessi fuistis habuisse et recepisse et portare in
comanda dicti patris mei ad partes ultramarinas ... fuit per vos michi nomine predicto bene et cetera satisfactum...", AHPB, Bernat Sans, Manual 1406, març, 6 - 1406, setembre, 3, f. 30.
} 
Quasi 35 anys després dels fets de 1391, seguim trobant famílies amb membres de les dues religions actuant de manera solidària. Aquest és el cas d'una família de jueus de la vila de Solsona. En instrument datat el dia 12 d'abril de 1426, Guillem Fivaller, convers, corredor d'orella, ciutadà de Barcelona, fill de Astruch Bendit, jueu de Solsona, nomena procurador seu el seu germà Cresques Bendit, jueu de Solsona, perquè rebi en el seu nom les quantitats de diners que li deu Jaffuda de Tolosa, jueu d'Agramunt. (Vegeu: Apèndix Documental, doc. 10; Apèndix d'Arbres Genealògics, 6. Família d'Astruch Bendit).

No manquen, però, els casos de ruptura matrimonial o divorci ${ }^{21}$ en el cas de la conversió d'un dels esposos, com podem veure tot seguit. En instrument datat el dia 12 de febrer de 1392, Caterina, conversa, dita Mayrona quan era jueva, i abans de la seva conversió muller de Pere de Pla, corredor d'orella, ciutadà de Barcelona, convertit al Cristianisme abans de la seva muller i ara mullerat amb una altra, fa donació a Agnès, filla d'ella i del dit Pere de Pla, conversa, dita Bonadona abans de la seva conversió, muller del també convers Floyno Bonanat, dels drets sobre 50 lliures que li deuen Issac Ferrer, jueu de Barcelona, i la muller d'aquest, conversa, dita Gojo abans de la seva conversió. (Vegeu: Apèndix Documental, doc. 2; Apèndix d'Arbres Genealògics, 7. Ruptura del matrimoni de Caterina).

El trencament del vincle matrimonial comportava la devolució del dot i de l'esponsalici a la muller. Es per això que, en instrument datat el dia 3 de setembre de 1392, Antigona, conversa, quan era jueva dita Estregua i llavors muller d'Issac Mercadell, jueu de Calaf, nomenà procurador seu el seu pare Francesc Bertran, convers, dit Biona de Piera quan era jueu, perquè demanés del seu exmarit el dot, l'esponsalici i els drets que li pertanyessin tant per raó del dot i l'esponsalici com per raó de la seva provisió fins que es va fer cristiana $^{22}$. (Vegeu: Apèndix Documental, doc. 4; Apèndix d'Arbres Genealògics, 8. Família de Francesc Bertran).

Un altre cas de ruptura del vincle matrimonial el trobem en un instrument datat el dit 17 de maig de 1411, segons el qual Pere d'Ortafà, convers, sabater, ciutadà de Barcelona, fill de Francesc Ros, convers, sastre, i d'Astruga, difunta, jueva, ambdós de la vila de Balaguer, reconeix rebre de Blanquina, amb la qual contraurà matrimoni, un dot de 20 lliures. Blanquina era filla d'Isaac Torquós, jueu de la vila de Castelló d'Empúries, i de Margarida, ara conversa i de nou maridada amb Pere de Gurrea, convers, sastre i ciutadà de Barcelona. (Vegeu Apèndix Documental, doc. 8; Apèndix d’Arbres Genealògics, 9. Família de Francesc Ros i Isaach Torquós).

\footnotetext{
${ }^{21}$ Vegeu sobre aquest tema, que aplica l'anomenat "privilegi paulí", l'article Divorce, dins Dictionnaire de Drolt Canonique, t. IV, Paris 1949, col. 1318.

${ }^{22}$ En l'arbre genealògic esmentat en el text, a més a més d'Antigona, el seu pare i el seu exmarit, consten la seva mare Caterina, conversa i els seus germans, Eulàlia i Pere Bertran, conversos i havent contret matrimoni. Aquests manquen en el document de l'apèndix documental. Hem tret aquestes dades d'altres instruments de diversos protocols.
} 


\section{L’ACCÉS DELS CONVERSOS A L'ESTAT CLERICAL}

Com hem dit, un tema molt debatut, en tractar el tema dels jueus conversos, és el de la sinceritat de llur conversió. ¿Pot considerar-se l'accés al clergat una prova de llur sinceritat? La resposta ens la donaria la biografia de cada un dels conversos que reberen alguna orde sagrada. Els Registra ordinatorum que es conserven a l'Arxiu Diocesà de Barcelona ens mostra els conversos que accediren al ritus de la tonsura i entraren en la classe dels clergues. En el quadre fet "ad hoc" consten tots els conversos que reberen la tonsura a partir de 1391 (el primer registre d'un convers tonsurat és de 1392) fins l'any 1442, a partir del qual no hem trobat la menció explícita de convers. En aquest quadre transcrivim els noms tal com es troben en els Registra ordinatorum o Registres dels ordenats de la diòcesi de Barcelona. Tan sols hi hem afegit el nom jueu abans de la conversió del tonsurant o del seu pare, si ha estat possible trobar-lo. (Vegeu Apèndix de Quadres, 2. Registres dels Ordenats).

Conversions massives, persistència dels jueus no conversos dins la societat, malgrat que minvant, ruptura de la unitat religiosa dins la família i, a vegades, dels lligams matrimonials, intent de recuperació econòmica, exercici dels mateixos oficis, cohessió fortament arrelada entre els conversos i també amb els no conversos o jueus tant en els aspectes socials com els econòmics. Sospita dels cristians de natura sobre la sinceritat dels conversos. Res d'estrany, doncs, que el convers, malgrat tot, es veiés, com hem dit més amunt, a si mateix vivint en una "societat transitòria" al marge de les dues religions, la cristiana i la jueva. 


\section{APÈNDIX DOCUMENTAL}

1392, febrer, 6. Barcelona.

Ferrer de Gualbes, convers, dit Issac Bonsenyor Gracià quan era jueu, procurador del seu pare Bonsenyor Gracià, jueu, i del seu germà Mosse Bonsenyor Gracià, jueu, reconeix haver rebut les quantitats a ells degudes per Guerau Folch, Guillem Castellar i Constança, esposa de Guillem Castellar, de la vila de Cervelló.

AHPB, Pere Claver, Llibre comú 1391, desembre, 7-1393, agost, 20, fol. 28 r.

Sit $^{\mathrm{a}}$ omnibus notum quod ego Ferrarius ${ }^{\mathrm{b}}$ de Gualbis, conversus, qui, antequam fuissem christianus, nominabar Issach Bonsenyor Gracia, procurator ad hec et alia constitutus a Bonsenyor Gracia, patre, et Mosse Bonsenyor Gracia, fratre meis, prout de mea procuratione liquet publico instrumento facto Tiviçe comitatus Montaneorum de Prades, quarta die mensis septembris proxime lapsi, et clauso per Petrum Maymoni, de Tiviça, regia auctoritate notarium publicum per totam terram et dominationem illustrissimi domini regis Aragonum, nomine meo proprio et nomine procuratorio predicto confiteor et recognosco vobis Geraldo Folch, Guillermo Castellà et Constancie, uxori dicti Guillermi, de villa Sancti Vincentii de Cervilione, quod fuit per vos michi dictis nominibus satisfactum voluntati mee super omnibus et singulis peccunie quantitatibus que per vos michi seu dictis meis principalibus deberentur usque ad hanc diem presentem tam cum scripturis tertiorum factis sive ${ }^{c}$ in curia venerabilis vicarii sive ${ }^{d}$ in curia venerabilis baiuli Barchinone, quam etiam alias quovis contractu vel obligatione. Et ideo dictis nominibus renuntio exceptioni dicte satisfactionis a vobis non habite et non recepte et per vos michi non facte, et doli mali et in factum actioni, et omni alii iuri, rationi et consuetudini contra hec repugnantibus. Facio dictis nominibus de omnibus et singulis peccunie quantitatibus supradictis, que per $v^{\mathrm{e}}{ }^{\mathrm{e}}$ seu alterum vestrum michi seu dictis meis principalibus deberentur insimul vel divisim usque hanc dictam diem, ut prefertur, bonum et perpetuum finem et pactum de ulterius non petendo et de non agendo in iudicio vel extra, in posse notarii infrascripti vallatum stipulatione solemni. Mandans dictis nominibus quibuscumque notariis et curiarum scriptoribus, quatenus ad solam vestri requisitionem et huius instrumenti hostensionem vobis cancellent et deleant omnes [..] notulas instrumentorum et alias quascumque quibus appareat vos michi seu dictis meis principalibus fore obligatum usque in hanc dictam diem, et dum ego eas et ea nunc pro tunc et tunc pro nunc casso, irrito et anullo et pro non factis cum presenti penitus haberi volo taliter quod deinde non possim vobis seu vestris in aliquo obesse ${ }^{\mathrm{f}}$ nec michi nec $^{\mathrm{g}}$ meis nec dictis meis principalibus seu suis in aliquo prodesse.

Actum est hoc Barchinone, sexta die febroarii, anno a nativitate Domini $\mathrm{M}^{\circ} \mathrm{CCC}^{\mathrm{o}}$ $\mathrm{XC}^{\mathrm{o}}$ secundo.

Sig + num Ferrarii de Gualbis, predicti, qui hec laudo nominibus predictis.

Testes huius rei sunt: Galcerandus de Turri et Arnaldus Canyelles [..]. ${ }^{\mathrm{g}}$

a. Al marge esquerre clausum traditum.- b. Damunt el nom, dues ratlletes obliqües per a indicar la ferma.c. sive interlineat $i$ escrit damunt tam ratllat.- d. sive interlineat i escrit damunt quam ratllat.- e. Segueix ratllat michi seu.- f. obesse interlineat $i$ escrit damunt prodesse ratllat.- g. Tot instrument ratllat amb tres ratlles verticals. 
1392, febrer, 12. Barcelona.

Caterina, conversa, dita Mayrona quan era jueva, i abans de la seva conversió muller de Pere de Pla, convers, corredor d'orella, ciutadà de Barcelona, $i$ ara mullerat amb una altra, fa donació a Agnès, filla d'ella i del dit Pere de Pla, conversa, dita Bonadona abans de la seva conversió, muller del també convers Floyno Bonanat, els drets sobre 50 lliures que li deuen Issac Ferrer, jueu de Barcelona, i la muller d'aquest, conversa, dita Gojo abans de la seva conversió.

AHPB, Bernat Nadal, Manual 1392, gener, 4-1392, juliol, 11, fol. 29v.

Caterina, ${ }^{\mathrm{a}}$ conversa ${ }^{\mathrm{b}}$ que fui uxor Petri de Plano, curritoris auris, civis Barchinone, olim iudei, nunc ad fidem catholicam conversi, qui ante suum babtismum vocabatur Issach Xam, quique, antequam ego conversa essem, fuit conversus et aliam duxit in uxorem, et ego tunch vocabar Na Mayrona, attendens plura grata et cetera per vos dominam Agnetem, filiam meam et dicti Petri de Plano, uxorem Floyno Bonanati, conversi, olim iudei Barchinone, que ante vestrum babtismum vocabimini Bonadona, michi exhibita et cetera; attendens etiam gratuitorum servitiorum et cetera, ideo gratis et cetera dono vobis dicte filie mee et vestris et cetera omnes illas quinquaginta libras monete Barchinone de terno, quas michi debet Issachus Ferrarii, iudeus Barchinone, et domina [..], ${ }^{\mathrm{c}}$ eius uxor, conversa, que ante suum babtismum vocabatur $\mathrm{Na}$ Gojo, cum scriptura tertii inde facta in curia baiuli Barchinone die et anno in ea contentis, et pro qua quidem quantitate sive pro securitate eiusdem dicti coniuges impigneraverunt michi quoddam hospitium, quod ipsi habebat et possidebant in callo maiori dicte civitatis in vico vocato de la Scola d'En Massot. Hanc autem donationem et cetera, sub tali pacto: quod ex predictis quiquaginta libris, cum eas habueritis, detis michi vel meis, incontinenti cum inde fueritis requisita, undecim libras. Et extraho et cetera. Cedens iura et cetera. Quibus et cetera. Constituens et cetera. Dicens et cetera. Promittens predicta rata et cetera, et non revocare et cetera. Renuntio et cetera. Hec igitur et cetera. Ad hec ego dicta Agnes, ${ }^{\mathrm{d}}$ laudans predicta et cetera, promitto dare predictas undecim libras et cetera. Sine et cetera. Dampna et cetera. Credatur et cetera. Obligo bona et cetera. Iuro et cetera. Hec igitur et cetera. Testes: Petrus Bonaora, curritor auris, Iohannes Boni, textor velorum de sedaços, conversi, et Iohannes Cijar, scriptor, cives Barchinone.

a. Damunt el nom, dues ratlletes obliqües per a indicar la ferma i l'abreviatura iur (iuravit) per a indicar el jurament.- b. conversa interlineat.- c. Indiquem amb [..] un espai en blanc puntuat per al nom cristià que no va ser copiat.- d. Damunt el nom, les dues ratlletes de la ferma.

1392, febrer, 29. Barcelona

Lleonard Ferrer, convers, dit Bonjuha Bonsenyor quan era jueu, pare, $i$ Vidal Bonjuha, jueu, fill, prometeren pagar a Dolça, conversa, dita Vidala quan era jueva, muller de David Aron, jueu, 15 lliures. Dolça cedí el seu dret 
contra pare i fill a Francesc Burgués, convers, dit Vidal Alcacauny quan era jueu, sobre 14 lliures $i 9$ sous. Pare i fill pagaren les 14 lliures $i 9$ sous.

AHPB, Pere Claver, Llibre comú 1391, desembre, 7-1393, agost, 20, fols. 40v-41r.

Die iovis, $\mathrm{XXIX}^{\mathrm{a}}$ die febroarii, anno predicto.

Sit omnibus notum quod ego Franciscus ${ }^{\text {a }}$ Burguesii, conversus, qui antequam venirem ad fidem catolicam nominabar Vitalis Alcacauny, attendens vos Leonardum Ferrarii, conversum, qui, antequam veniretis ad dictam fidem catholicam, eratis nominatus Boniuha Bonsenyor, et Vitalis Bonjuha, filius vester, et uterque (sic) vestrum insolidum scripsisse et sub pena tertii solvere promisisse Dulcie, uxori Davi Aron, iudei, nunc converse, vocate Vidala, quindecim libras monete Barchinone de terno certo termino, diu est lapso, cum iudiciali scriptura facta in curia venerabilis baiuli Barchinone sub kalendario XVIII ${ }^{\mathrm{e}}$ diey augusti anni a nativitate Domini millesimi CCC $^{\mathrm{i}}$ octuagesimi octavi; attendens etiam dicta Vitala, die veneris, XXVII ${ }^{\mathrm{a}}$ octobris proxime lapsi, in solutum consimilis peccunie quantitatis michi dedisse locum et cessionem contra dictos patrem et filium et eorum bona in quatuordecim libris et novem solidis dicte monete, restantibus ex dictis quindecim libris, prout de dicta cessione liquet per iudicialem scripturam scriptam et continuatam in fine dicte tercie scripture; attendens etiam post dictam cessionem per vos dictum Leonardum fuisse michi satisfactum voluntati mee in dictis XIIII ${ }^{\text {or }}$ libris et novem solidis et me velle vobis dictam tertii scripturam, nisi esset ${ }^{\mathrm{b}}$ empara seu preconitzacio de mandato domini regis facta de et pro debitis conversorum et iudeorum, idcirco confitens predicta in veritate consistere [..]. ${ }^{c}$

Testes huius rei sunt: Laurentius Masó, notarius, et Franciscus Solerii, scriptor, cives Barchinone.

a. Damunt el nom, dues ratlletes obliqües per a indicar la ferma.- b. Segueix ratllat ep.- c. L'instrument acaba aquí.

1392, setembre, 3. Bacelona.

Antigona, conversa, quan era jueva dita Estregua i llavors muller d'Isaac Mercadell, jueu de Calaf, nomena procurador seu el seu pare Francesc Bertran, convers, dit Biona de Piera quan era jueu, perquè demani del seu exmarit el dot, l'esponsalici $i$ els drets que li pertanyen tant per raó del dot $i$ l'esponsalici com per raó de la seva provisió fins que es va fer cristiana.

AHPB, Arnau Piquer, Manual 1391, octubre, 16-1392, desembre, 24, fol. 129r. secundo.

Die martis, III die septembris, anno a nativitate Domini M CCC nonagesimo

$\mathrm{Sit}^{\mathrm{a}}$ omnibus notum quod ego Antigona ${ }^{\mathrm{b}}$, conversa, olim, dum iudea eram, ${ }^{\mathrm{c}}$ vocata Streugua, et tunc uxor Isach Mercadell, iudey de Calaff, ex certa scientia constituo et ordino vos Francischum Bertrandi, conversum, patrem meum, ${ }^{\mathrm{d}}$ olim, ${ }^{\mathrm{e}}$ dum iudeus eratis, vocatum Biona de Piera, ${ }^{f}$ presentem, onus huius procurationis in vos sponte suscipientem, procuratorem meum certum et specialem ad petendum, exhigendum et recipiendum pro me et nomine meo a dicto Isach Mercadell, ${ }^{\mathrm{g}} \mathrm{olim}$ 
marito meo, et bonis suis dotem meam et sponsalitium meum et ${ }^{\mathrm{h}}$ alia iura universa et singula $a^{i}$ michi competentia in bonis dicti olim mariti mei tam ratione dotis et sponsalitii mei predictorum quam etiam ratione provisionis mee per vos michi facte a tempore quo christiana sum citra. Et inde compositiones, transactiones ${ }^{\mathrm{k}}$ et avinentias faciendum $^{1}$ et firmandum cum illis clausulis de seu pro eisdem necessariis et opportunis. Et inde apochas, fines, absolutiones, diffinitiones et cessiones, tam speciales quam generales, faciendum et firmandum, dando et concedendo vobis dicto procuratori plenum posse quod in et super predictis et ratione seu occasione predictorum possitis pro me et nomine meo coram quibuscumque curiis, iudicibus et personis, tam ecclesiasticis quam secularibus, comparere, de iure meo docere, querelas, tam primas scilicet quam secundas, proponere et audire, iusque super bonis meis firmare que pro firma sive firmis iuris obligare possitis, necnon agere, respondere, deffendere, excipere, proponere et replicare, libellum vel libellos offerre et recipere et littes etiam contestari, emparam vel ${ }^{\mathrm{m}}$ et emparas necnon secundas querelas facere $^{\mathrm{n}}$ et exponere, et ipsas emparas et scripturas quascumque pro predictis facientes $^{\mathrm{o}}$ cancellare et anullare seu cancellari et anullari facere seu eas ${ }^{\mathrm{p}}$ restituere, sacramentum calumpnie et veritatis dicende et cuiuslibet alterius generis iuramentum in animam meam prestare et $\mathrm{ab}$ adversa parte in animam suam prestari, petere testes et instrumenta et alia probationum genera producere et publicare, crimina et deffectus et alia opponere, disputare, allegare, renunciare et concludere in causa, et omnia que in littem requiruntur fieri et cuiuscumque generis sententias audire, et ab ipsa vel ipsis et a quolibet etiam gravamine allato et inferendo, cominato et cominando et a quocumque etiam processu facto et faciendo acceptato, si vobis visum fuerit, appellare, supplicare et reclamare vel predicta etiam anullare, apostolos petere [... $]^{q}$ recipere et presentare, et causam seu causas appellationis, supplicationis, reclamationis et nullitatis prosequi [..] finire, protestari et requirere, et protestationibus et requisitionibus respondere et replicare et [..] facere et recipere publica instrumenta. Et omnia alia facere super predictis et circa predicta pro me et nomine mei [..] sunt ad hec utilia ac etiam opportuna, etiam si talia fuerint que de iure vel de facto mandatum exhigerent [..] et que ego facere possem si personaliter interessem. Et volens vos dictum procuratorem meum super predictis relevare ab omni onere satisdandi, fideiubendo in hiis pro vobis, promitto vobis et vobis etiam notario infrascripto, tanquam publice persone, pro personis omnibus et singulis quarum interest vel intererit stipulanti, iudicio sisti et iudicatum solvi cum suis clausulis universis, me semper habere ratum, gratum et firmum quicquid per vos dictum procuratorem meum super predictis et circa predicta pro me et nomine meo procuratum fuerit sive gestum et nullo tempore revocare sub bonorum meorum omnium $^{\mathrm{r}}$ ypotheca.

Actum est hoc Barchinone.

Testes huius rei sunt: Petrus Vives, sartor, Petrus Simon, libraterius, conversi, cives, et Guillermus de Rivo, notarius, habitator Barchinones

a. Al marge esquerre clausum traditum.- b. Damunt el nom, dues ratlletes obliqües per a indicar la ferma.c. dum iudea eram intelineat.- d. Segueix ratllat vocatum Biona.- e. olim interlineat.- f. vocatum Biona Piera intelineat.- g. Isach Mercadell intelineat.- $\mathrm{h}$. Segueix ratllat alius.- i. universa et singula interlineat.k. transactiones interlineat.- 1. Segueix ratllat de se et pro eisdem.- m. emparam vel interlineat.- n. Segueix ratllat sive.- o. Pro predictis facientes interlineat.- p. eas interlineat.- q. Un estrip impedeix la lectura de part de l'instrument, cosa que indiquem amb [..].- r. Segueix ratllat ap.- s. Tot l'instrument ratllat amb tres ratlles verticals. 
1392, octubre, 16. Barcelona.

Venda d'una casa per Joan Bertran, convers, dit Samuel Benvenist quan era jueu, fill del jueu Ferrer Benvenist, i el seu oncle Samuel Benvenist, jueu, a Esteve sa Torre, apotecari, ciutadà de Barcelona. Reben 4.400 sous, que són part del preu de la casa.

AHPB, Francesc de Pujol, Manual 1392, agost, 9-1392, novembre, 29, fol. 33r.

Instrumentum $^{\mathrm{a}}$ venditionis per Iohannem Bertran, conversum, olim vero vocatum Samuelem Benvenist ${ }^{\mathrm{b}}$, minorem dierum, filium Ferrarii Benvenist, ${ }^{\mathrm{c}}$ et Samuelem Benvenist, iudeum, filium Benvenist Samuel, quondam, iudei, facte venerabili Stephano ça Torre, ${ }^{\mathrm{d}}$ apotecario, civi Barchinone, de quodam hospitio et cetera. In cedula.

Testes: Petrus Brulla, de villa Cocoliberi, et Petrus Celom, scutifferi, comorantes Barchinone, et Franciscus Fuxi ac Raymundetus de Marginibus, cives Barchinone.

Item, dicti venditores firmarunt apocham de quatuor mille quadringentis solidis ex pretio dicti hospitii et cetera. In dicta cedula.

Testes predicti. ${ }^{\mathrm{e}}$

a. Al marge esquerre Vacat quia inferius est.- b. Segueix ratllat et.- c. filium Ferrarii Benvenist interlineat.d. Segueix ratllat in.- e. Tot instrument ratllat amb una creu en aspa.

1394, març, 4. Barcelona.

Els germans Pere Benet de Rexach, convers, dit Benet Belshom quan era jueu, $i$ Mosse Belshom, jueu, ambdós de Girona, hereus universals a parts iguals de llur pare $i$ germà, difunts, ambdós dits Vidal Belshom, ratifiquen $i$ confirmen la venda d'una casa feta per Samuel Benvenist, jueu de Barcelona, a Pere Pascasi, doctor en ambdós drets, ciutadà de Barcelona.

AHPB, Arnau Piquer, Manual 1393, desembre, 25-1394, juliol, 31, s.n.

Die mercurii, IIII ${ }^{\mathrm{a}}$ die martii, anno a nativitate Domini $\mathrm{M}^{\mathrm{o}} \mathrm{CCC} \mathrm{XC}$ quarto.

Nos $^{\mathrm{a}}$ Petrus ${ }^{\mathrm{b}}$ Benet de Rexach, conversus, olim nominatus Benet Belshom, filius et ${ }^{\mathrm{c}}$ frater Vitalis Belshom, quondam, iudeorum civitatis Gerunde, ${ }^{\mathrm{d}}$ Mosse ${ }^{\mathrm{e}}$ Belshom, iudeus Gerunde, similiter filius et frater predictorum Vitalis Belshom, quondam, et heredes universales equis partibus predictorum patris et fratris nostrum, quondam, gratis et ex certa scientia laudamus, approbamus, ratifficamus et confirmamus ${ }^{\mathrm{f}}$ vobis venerabili et discreto Petro Paschasii, utriusque iuris doctori, civi Barchinone, venditionem quam Samuel Benvenist, iudeus Barchinone vobis fecit de hospitio et cetera et possessione quam eo tenetis et recepistis. ${ }^{\mathrm{g}}$

Testes: Martinus de Moralibus et Francicus de Vilagayà, comorantes, et Astrugus ça Porta, iudeus Barchinone. 
a. Al marge esquerre In libro venditionum.- b. Damunt el nom, dues ratlletes obliqües per a indicar la ferma i l'abreviatura iur (iuravit) per a indicar el jurament.- c. et interlineat.- d. Segueix ratllat heresque eorum.- e. Damunt el nom, les dues ratlletes de la ferma i l'abreviatura iur.- f. Segueix ratllat venerabili.g. Al marge esquerre Debet dictari largo modo ad cognitionem ipsius Petri Pascasii quia ita fuit firmatum.

1404, gener, 30. Barcelona

Vidal de Beses, jueu de Solsona, fill de Juceff de Beses, jueu de Solsona, promet al seu germà Joan de Cardona, convers, mercader, ciutadà de Barcelona, que per raó del matrimoni entre Joan de Cardona i Elionor, filla de Berenguer de Cortil, convers, mercader, ciutadà de Barcelona, i per amor fraternal, que durant tres anys, a partir de la propvinent festa de Pasqua, proveirà els dits cònjuges i llurs fills en aliments d'acord amb la seva condició social.

AHPB, Pere Claver, Llibre comú 1403, desembre, 29-1404, novembre, 5, fols. 18v-19r.

In Dei nomine. Noverint universi quod ego Vitalis de Beses, iudeus ville Solsone, filius Iuceffi de Beses, iudei ville predicte, non vi nec dolo aut metu inductus seu compulsus, sed gratis et ex mera mea certa scientia, contemplatione matrimonii selebrati, diu est, inter Iohannem Cardona, conversum, fratrem meum, et dominam Elianorem, filiam vestri Berengarii de Cortilio, conversi, mercatoris, civis Barchinone, et alias fraternitatis amore inductus, per me et meos heredes et successores, convenio et promitto vobis dicto Berengario de Cortilio et notario etiam infrascripto, tanquam publice persone, hec a me pro vobis et dictis fratre meo et eius uxore et filiis ipsorum natis et nascituris recipienti et legittime stipulati, quod ego a primo ${ }^{\mathrm{a}}$ venturo festo Pasce ad tres annos ex tunc proxime subsequentes et completos, de meo proprio et sine $^{\mathrm{b}}$ missione $^{\mathrm{c}}$ aliqua vestri dicti Berengarii et ipsorum coniugum et filiorum eorumdem natorum et nasciturorum, providebo ipsos coniuges in cibo et potu condecenter iuxta eorum qualitatem et etiam ipsorum filios natos et infra dictum tempus nascituros sive sint vel fuerint masculini sive feminini sexus et hec sine aliqua excusatione, exceptione et impedimento ac contradictione et absque omni dampno, missione et interesse vestri et dictorum coniugum et ipsorum filiorum predictorum. Et quod restituam et solvam vobis dicto Berengario nomine ipsorum coniugum et ipsorum filiorum seus ipsis coniugibus, si quas missiones, dampna et interesse vos nomine ipsorum coniugum seu filiorum ipsorum predictorum, seu dictos coniuges opportuerit facere aut modo aliquo sustinere ${ }^{\mathrm{d}}$ in iudicio vel extra culpa mei seu meorum, recusantis seu recusantium predicta per me promissa adimplere et sive sit ratione dicte provisionis sive ratione petitionis eiusdem et ${ }^{\mathrm{e}}$ dependentium ex eadem sive etiam alias. Super quibus missionibus, dampnis et interesse credatur et credi volo dicto Berengario et coniugibus supradictis et utrique ipsorum plano et simplici verbo, nullo alio probationum genere requisito. Et pro predictis omnibus et singulis complendis et attendendis, tenendis et observandis, obligo vobis dicto Berengario nomine dictorum coniugum et ipsorum filiorum et dictis coniugibus et filiis ipsorum natis et nascituris in posse et manu notarii et infrascripti ut supra stipulanti omnia et singula bona mea, mobilia et inmobilia, habita et habenda, etiam privilegiata. Et ineo tamen michi quod si forte infra tempus dictorum trium annorum per vos nomine ipsorum coniugum seu dictos coniuges non fuerit mota questio ratione dicte provisionis contra me seu meos, quod post lapsum temporis predicti non valeat moveri 
contra me seu bona mea per vos seu ipsos coniuges modo aliquo sive causa questio aliqua, petitio seu demanda occasione promissionis predicte seu dependentium $\mathrm{ex}^{\mathrm{f}}$ eadem, quoniam sub hoc pacto dictam promissionem et obligationem facio.

Actum est hoc Barchinone, $\mathrm{XXX}^{\mathrm{a}}$ die ianuarii, anno a nativitate Domini millesimo quadringentesimo quarto.

Sig + num Vitalis de Beses, iudei, predicti, qui hec laudo et firmo.

Testes huius rei sunt: Bernardus de Pinosio, conversus, ${ }^{\mathrm{g}}$ civis Barchinone, et Bonastruch ${ }^{\mathrm{h}}$ del Mestre, iudeus Solsone.

a. Segueix ratllat a primo.- b. Segueix ratllat et.- c. Segueix ratllat da.- d. sustiner interlineat $i$ escrit damunt sustinere in.- e. Segueix ratllat dependend.- f. Segueix ratllat eidem.- g. Segueix ratllat dl.

1411, maig, 17. Barcelona

Pere d'Ortafà, convers, sabater, ciutadà de Barcelona, fill de Francesc Ros, convers, sastre, i d'Astruga, difunta, jueva, ambdós de la vila de Balaguer, reconeix rebre de Blanquina, filla d'Issac Torquós, jueu de la vila de Castelló d'Empúries, $i$ de Margarida, ara conversa $i$ muller de Pere de Gurrea, convers, sastre $i$ ciutadà de Barcelona, 20 lliures, que són el dot de Blanquina, amb la qual contraurà matrimoni.

AHPB, Jaume de Trilla, Capibrevium comune 1411, gener, 11-1411, desembre, 27, fol. 80r-v.

In Dei nomine. Noverint universi quod ego Petrus ${ }^{a}$ Dortafà, sutor, conversus, ${ }^{\mathrm{b}}$ civis Barchinone, filius Francisci Ros, conversi, sartoris, et domine Astruge, quondam, iudee civitatis Balagarii, confiteor et recognosco vobis Blanquine, quam, Deo volente, ducere debeo in uxorem, filie Issach Torquós, iudei, retzolerii, ville Castilionis Impuriarum, et domine Margarite, eius uxoris, converse, habitatricisque Barchinone, nunc vero uxoris Petri de Gorrea, conversi, sartoris, civis dicte civitatis, quod habui et recepi a vobis sive pro vobis in dotem et pro dote vestra ac nomine dotis vestre viginti libras monete Barchinone de terno. Et ideo renuntiando exceptioni non numerate peccunie et dotis predicte non ${ }^{\mathrm{c}}$ habite et non recepte, et actioni in factum et doli, et omni alii iuri, rationi et consuetudini contra hec repugnantibus, et propter hanc dotem a vobis sive pro vobis receptam, facio vobis augmentum seu donationem propter nuptias de decem libris Barchinone, et sic sunt in suma omnes dicti denarii inter dotem et augmentum seu donationem propter nuptias triginta libre eiusdem monete, quas assigno et assecuro vobis et vestris in et super omnibus et singulis bonis meis, mobilibus et inmobilibus, habitis et habendis. Et convenio et promitto vobis quod omnes predictas triginta libras reddam, restituam et solvam vobis et vestris, aut quibus volueritis loco vestri, ad vestram et eorum voluntatem, in omnem scilicet casuum ( $\mathrm{sic}$ ) et eventum restituende et solvende dotis, incontinenti scilicet cum restitutioni et solutioni dotis locus fuerit, sine omni videlicet dilatione, excusatione et exceptione et absque omni dampno et missione vestri et vestrorum. Et quod restituam et solvam vobis et vestris ad vestram et eorum voluntatem indilate, si quas missiones, dampna et interesse vos vel vestros opportuerit facere vel modo aliquo sustinere pro predicta vestra dote in totum vel in parte pettenda, exhigenda, recuperanda et habenda a me vel bonis meis in iudicio vel extra iudicium. Super quibus quidem missionibus, dampnis et interesse credatur vobis et 
vestris plano et simplici verbo, nullo alio probationum genere requisito. Et habeatis, teneatis et iure vestri proprii sponsalitii possideatis omnes predictas triginta libras ut rem dotalem totius videlicet vite vestre cum marito et sine marito, cum infante et sine infante et absque vinculo, obstaculo et contradictione mei et meorum. In die autem obitus vestri habeatis vos ad omnes vestras voluntates in omni casu libere faciendas dictas viginti libras dotales. Predicte vero decem libre, de quibus vobis feci augmentum seu donationem propter nuptias, sint et revertantur post sepedictum obitum vestrum infanti seu infantibus aut liberis qui de me in vobis vivi fuerint superstites procreati. Quibus infanti seu infantibus aut liberis, qui de me in vobis vivi fuerint superstites procreati in casu existentie eorumdem, ego nunc pro tunc ipsas decem libras dicti augmenti dono, confero et assigno in manu et posse notarii infrascripti, tanquam publice persone, pro predictis infante seu infantibus aut liberis et pro omnibus aliis etiam personis, quarum interest et intererit, recipientis et paciscentis ac etiam legitime stipulantis. Quod si ad obitum vestrum infans vel infantes aut liberi de me in vobis procreati vobis vivi superstites deffuerint, quod absit, in hoc casu predicte decem libre revertantur michi, si tunch vixero, sin autem heredi meo aut illi vel illis, cui seu quibus ego voluero seu ordinavero verbis vel testamento aut alias quovis modo. Insuper convenio et promitto vobis dicte Blanquine et vestris quod predicta omnia et singula semper rata et firma habebo, tenebo et observabo et quod contra ea non faciam vel veniam iure aliquo, causa vel ratione. Et pro hiis complendis et firmiter attendendis, tenendis et observandis, obligo vobis et vestris omnia et singula bona mea, mobilia et inmobilia, habita et habenda. Hec igitur que dicta sunt supra, facio, paciscor et promitto ego dictus Petrus Dortaffa per me et omnes heredes et successores meos quoscumque vobis dicte Blanquine, future sponse mee, et vestris et notario infrascripto, ut publice persone, pro vobis et vestris et pro omnibus aliis etiam personis, quarum interest et intererit, recipienti et paciscenti ac etiam legitime stipulanti.

Actum est hoc Barchinone, septima decima die madii, anno a nativitate Domini millesimo quadringentesimo undecimo.

Sig + num Petri Dortaffà, predicti, qui hec laudo, concedo et firmo. cives Barchinone]. ${ }^{\mathrm{d}}$

Testes huius rei sunt [Franciscus Morató, sutor, et Iacobus Calladell, sartor,

a. Damunt el nom, dues ratlletes obliqües per a indicar la ferma.- b. conversus interlineat.- c. Segueix ratllat mi.- d. Els noms dels testimonis consten en l'últim instrument referent al compromís matrimonial.

1417, desembre, 30. Barcelona

Francesc Sala, frare de l'Orde de Predicadors, Inquisidor General en els dominis del rei d'Aragó i lloctinent en aquest acte del vicari general del Bisbe de Barcelona, declara que Na Yoya, conversa, indüda per parents $i$ amics jueus, tornà al judaïsme praticant els ritus jueus, anant a la sinagoga, prenent els aliments permesos als jueus i el pa àzim i observant les festivitats jueves. En haver estat processada, Yoya abjurà i rebé l'absolució d'excomunió major, tot complint la penitència imposada.

AHPB, Pere Puig, Llibre comú 1417, desembre, 10-1418, julio, 31, s.n 
In nomine Domini nostri Ihesu Christi et eius gloriossisime genitricis virginis Marie ac totius curie civium supernorum. Universis et singulis Christi fidelibus, ad quos presens publicum pervenerit instrumentum, seu quibus fuerit quomodolibet presentatum, nos frater Franciscus Sala, ordinis Fratrum Predicatorum, in sacra pagina magister, et in dominio et ditione illustrissimi domini regis Aragonum inquisitor heretice pravitatis, a Sancta Sede Apostolica specialiter delegatus, et in hoc actu locum tenens honorabilis et providi viri domini Ferrarii de Podiolo, canonici Sedis Barchinone, in spiritualibus et temporalibus reverendissimi in Christo patris et domini domini Andree, miseratione divina episcopi Barchinone, in remotis agentis, vicarii generalis, salutem et trium[p]hum ${ }^{\mathrm{a}}$ fidei catholice in celestibus reportare. Vobis et cuilibet ${ }^{\mathrm{b}}(\mathrm{sic})$ vestrum notum facimus serie cum presenti quod dilecta pro nunc in Christo filia domina na Yoya, neophita seu conversa, que fuit uxor Iohannis Ermengol, quondam, sartoris, civis Barchinone, que suggestione diaboli, humani generis inimici, qui ubi virtutum segetes uberius videt exsurgere, ibi scandalorum vepres et desidiorum zizanias ac sacrosancte fidei catholice ${ }^{c}$ errores satagit cumulatius seminare, necnon et quorumdam iudeorum sibi in gradu seu linea parentele coniunctorum et aliorum inducta pariter et seducta, dudum spreta, quam susceperat, fide Christi, et ut canis rabida ad vomitum rediens, pluries iudeorum familiaritates fuit sectata et cum eis tam Cervarie, Terracone, in parrochia Sancti Vincentii de Ortis quam etiam alibi, in festivitatibus precipuis iudeorum fuit frequentissime conversata, eorumque sinagogas intravit et frequenter etiam visitavit, cibariaque iudeorum cum eorum serimoniis preparata necnon panes azimos in festivitatibus ipsorum paschalibus comedit, ipsorumque iudeorum et solemnitates coluit et etiam celebravit et quamplures ritus et serimonias execrabiles iudeorum tenuit et inviolabiliter observavit. Sed tandem ille $^{\mathrm{d}}$ sumpmus et misericors peramplus ${ }^{\mathrm{e}}$ sol oriens mundo in altissimis Dei Filius et Dominus Ihesus Christus, qui vult omnes homines salvos / fieri et ad agnitionem pervenire veritatis, quique pro salute humani ${ }^{\mathrm{f}}$ generis, nostram assumendo naturam, in sacratissime virginis Marie talamo texit trabe carnis nostre fragilis semetipsum, virginitatis sigillo inviolato procul dubio remanente, ipsam na Yoya Ermengola, tanquam ovem perditam ad gregem dominicum redire cupientem, eius sponse sancte matris $^{\mathrm{g}}$ Ecclesie Catholice restituit unitati et ad eius inviolabilis fidei glutinum misericorditer copulavit, videlicet quod dicta na Yoya Ermengola, divina gratia illustrata, adherendo consilio seniori, adiens presentiam nostri, Inquisitoris et locumtenentis vicarii generalis, bono animo et spontanea voluntate submittendo se correctioni sancte matris Ecclesie, culpam suam humiliter recognoscens, predicta sua crimina hereticalia coram nobis ${ }^{\mathrm{h}}$ in iudicio fuit flebiliter confessa, veniam et misericordiam de per eam, ut premittitur, comissis humiliter postulando. Quapropter nos, Inquisitor heretice pravitatis et locumtenens vicarii generalis antedicti, volentes Illum imytari qui perditis (sic) nonaginta novem ovibus centesimam venit perquirere ne periret, ipsam na Yoya Ermengola, facta per eam primitus, ut iura populi postulant, premissorum abiuratione, reconsiliavimus iuxta formam sancte matris Ecclesie consuetam, que non claudit suum gremium redeunti, et ad ipsius sancte matris Ecclesie reduximus unitatem et ipsam absolvimus a maioris excomunicationis sententia qua incurrerat causis superius expressatis, sibique pro comissis eam sententialiter condempnando iuxta sacrorum canonum statuta qualem decebat penitentiam iniunximus salutarem, prout hec omnia et alia in processu inde coram nobis accitato plenius et extensius continentur. Ideo, auctoritate apostolica qua fungimur, in hac parte intimantes omnia supradicta, cum hoc eodem publico instrumento requirimus et monemus ${ }^{\mathrm{i}}$ et ex nostra auctoritate rogamus omnes et singulos officiales ecclesiasticos et seculares et alias quascumque personas, humiles vel excelsas, quantumcumque prefulgeant dignitate, quatenus amodo ipsam na Yoya 
Ermengola ut veram et fidelem christianam et sancte matris Ecclesie filiam in omnibus et per omnia bene et caritative pertractent et eam occasione premissorum criminum in aliquo molestari sub penis contra oppositum facientes in iure canonico exaratis. In quorum omnium et singulorum fidem et testimonium presens publicum instrumentum sibi dicte na Yoya Ermengola fieri et tradi iussimus per nostrum notarium et scribam infrascriptum.

Quod est actum Barchinone, tricesima die mensis decembris, anno a nativitate ${ }^{\mathrm{i}}$ Domini millesimo quadringentesimo decimo octavo.

Sig + num mei fratris Francisci Sala, Inquisitoris heretice pravitatis et locumtenentis in hoc actu venerabilis vicarii generalis dicti domini episcopi Barchinone, predicti, qui hec laudamus, concedimus et firmamus.

Testes huius rei sunt: honorabilis Petrus Baturelli, miles, domiciliatus in civitate Barchinone, venerabiles et discreti religiosus frater Bartholomeus Nicholai, dicti ordinis Predicatorum, et Bernardus Martini, presbiter Barchinone.

a. trimuphum, al $m s$ triumhum.- b. cuilibet, al $m s$ cuiuslibet.- c. Segueix ratllat terelas.- d. ille interlineat i escrit damunt sump ratllat.- e. peramplus, al ms peranimphus.- f. Segueix ratllat geren.- g. Segueix ratllat ecclesie.- h. nobis, al ms vobis. Segueix ratllat et ex auta.- i. Segueix ratllat donni.

1426, abril, 12. Barcelona

Guillem Fivaller, convers, corredor d'orella, ciutadà de Barcelona, fill d'Astruch Bendit, jueu de Solsona, nomena procurador seu el seu germà Cresques Bendit, jueu de Solsona, perquè rebi en el seu nom les quantitats de diners que li deu Jaffuda de Tolosa, jueu d'Agramunt.

AHPB, Narcís Bru, Tertium manuale 1427, juliol, 19-1430, novembre, 7, s.n.

Noverint ${ }^{\mathrm{a}}$ universi quod ego Guillermus ${ }^{\mathrm{b}}$ Fivaller, conversus, ${ }^{\mathrm{c}}$ curritor auris, ${ }^{\mathrm{d}}$ civis Barchinone, filius Struchi Bendit, quondam, iudei ville Celsone, ex certa scientia constituo et ordino vos Cresques Bendit, iudeum dicte ville, fratrem meum, ${ }^{\mathrm{e}}$ presentem, procuratorem meum certum et specialem et ad subscripta generalem, ita quod specialitas generalitati non deroget nec e contra, videlicet ${ }^{\mathrm{f}}$ ad petendum, exhigendum, habendum et recipiendum pro me et nomine meo omnes et singulas res, peccunie quantitates, debita, instrumenta et alia quevis bona et iura que michi debeantur seu a me detineantur per Iaffudam de ${ }^{\mathrm{h}}$ Tolosa, iudeum de Agramunt, aut aliam quamvis personam nomine ipsius [.. $]^{\mathrm{i}}$ Et promitto vobis et notario infrascripto, tanquam publice persone, pro vobis et pro aliis etiam personis omnibus, quarum intersit et intererit, legittime stipulanti, paciscenti et recipienti. Necnon iuro sponte in animam meam per Dominum Deum et eius sancta quatuor Evangelia, manibus meis corporaliter tacta, me semper habere ratum, gratum, validum atque firmum quicquid per vos in predictis et circa ea actum, gestum fuerit sive etiam procuratum, et nullo tempore revocare sub bonorum meorum omnium ubique obligatione.

Actum est hoc Barchinone, duodecima die ${ }^{\mathrm{k}}$ aprilis, anno a nativitate Domini millesimo quadringentesimo vicesimo sexto.

Sig + num Guillermi Fivaller, predicti, qui hec laudo, firmo et iuro. 
Testes huius rei sunt: Macianus Castelló, iupponerius, et Berengarius Baluffer, sartor, cives Barchinone. ${ }^{1}$

a. Al marge esquerre clausum traditum.- b. Damunt el nom, dues ratlletes obliqües per a indicar la ferma.c. conversus interlineat.- d. Segueix ratllat conversus.- e. fratrem meum interlineat.- f. videlicet interlineat.- g. debita instrumenta interlineat.- h. Segueix ratllat tholo.- i. El mal estat del protocol impedeix la lectura de part del text que conté les clàusules habituals en tot nomenament de procurador, que no reprodü̈m.- $\mathrm{k}$. die interlineat.- 1 . Tot l'instrument ratllat amb tres ratlles verticals.

Fecha de recepción del artículo: noviembre 2006.

Fecha de aceptación y versión final: febrero 2007 
JOSEP HERNANDO

\section{APÈNDIX DE QUADRES}

1. Jaume de Trilla, Undecimum manuale 1390-1392

AHPB, Jaume Trilla, Undecimum manuale 1390, octubre, 12-392, gener, 26

\begin{tabular}{|c|c|c|c|c|}
\hline DATA & CONVERSOS & $\begin{array}{c}\text { JUEUS O NOM JUEU DEL } \\
\text { CONVERS }\end{array}$ & OFICT & FULI \\
\hline $1390 / 10 / 12$ & & $\begin{array}{l}\text { Jucefus Salamo Falcho } \\
\text { Sentou Abraham Mahie }\end{array}$ & & IV \\
\hline $1390 / 10 / 12$ & & $\begin{array}{l}\text { Mosse Sedoch } \\
\text { Sday Cresques } \\
\text { Ruven Levi } \\
\text { Mosse Roven } \\
\text { Sday Cresques } \\
\text { Issach de Piera }\end{array}$ & & $3 r$ \\
\hline $1390 / 10 / 25$ & & $\begin{array}{l}\text { Azday Cresques } \\
\text { Mosse Sadoch } \\
\text { Roven Levi, pare i } \\
\text { Mosse Roven, fill }\end{array}$ & $\begin{array}{l}\text { Tintorer } \\
\text { tintorer } \\
\text { tintorer }\end{array}$ & $5 \mathrm{v}$ \\
\hline $1390 / 11 / 14$ & & Samuel Benvenist & & TIr \\
\hline $1390 / 11 / 16$ & & Salamo Lobell Gracia & & $13 \mathrm{r}$ \\
\hline $1390 / 11 / 16$ & & $\begin{array}{l}\text { Juceffus Jafiel } \\
\text { Biona Bondia de Piera } \\
\text { Bonjuha Issach Delell } \\
\text { Struch Ranaya } \\
\text { Struch Jucef Provençal }\end{array}$ & & $13 \bar{v}$ \\
\hline $1390 / 11 / 17$ & & $\begin{array}{l}\text { Salomo Vidal sa Escaleta } \\
\text { Samuel Benvenist }\end{array}$ & & $14 \mathrm{r}$ \\
\hline $1390 / 11 / 24$ & & $\begin{array}{l}\text { Abram Vidal } \\
\text { Struch de la Cavalleria }\end{array}$ & & $16 \mathrm{~V}$ \\
\hline $1390 / 11 / 24$ & & $\begin{array}{l}\text { Centou Sabucsell } \\
\text { Salamó Jacob }\end{array}$ & sastre & $1 / \mathrm{v}$ \\
\hline $1390 / 12 / 05$ & & $\begin{array}{l}\text { Daviu Burgales, marıt } \\
\text { Maria, muller }\end{array}$ & cortiner & $2 \mathrm{Ir}$ \\
\hline $1390 / 12 / 31$ & & Astruch ça Porta & & $3 I V$ \\
\hline $1391 / 01 / 01$ & & $\begin{array}{l}\text { Abraham MandiI } \\
\text { [..] }\end{array}$ & & $31 \mathrm{v}$ \\
\hline 1391/01/02 & & Abraham Mandil & & $32 \mathrm{r}$ \\
\hline $1391 / 01 / 13$ & & $\begin{array}{l}\text { Samuel sentou de Palencia } \\
\text { Vidal Maçip de la Torra } \\
\text { Naçan Salamó }\end{array}$ & $\begin{array}{l}\text { coraler } \\
\text { coraler }\end{array}$ & $38 \mathrm{v}$ \\
\hline $1391 / 01 / 13$ & & $\begin{array}{l}\text { Astruch Bondavi Descortal } \\
\text { Abraham Benvenist } \\
\text { Abraham Samant }\end{array}$ & & $39 r$ \\
\hline $1391 / 02 / 07$ & & $\begin{array}{l}\text { SamueI Juceff } \\
\text { Salamó des Bon } \\
\text { Salamó des Benvenist }\end{array}$ & $\begin{array}{l}\text { sastre } \\
\text { sastre }\end{array}$ & $48 \mathrm{v}$ \\
\hline $1391 / 02 / 18$ & $\begin{array}{l}\text { Casasagia, Francesc, marit } \\
\text { Violant, muller }\end{array}$ & = Bonjach Comprat & $\begin{array}{l}\text { sastre - corredor } \\
\text { orella - porter rei }\end{array}$ & $53 \mathrm{v}$ \\
\hline $1391 / 02 / 28$ & & $\begin{array}{l}\text { Salamo Sabib } \\
\text { Salamó Atzara } \\
\text { Juceff Abbes }\end{array}$ & & $57 \mathrm{v}$ \\
\hline $1391 / 03 / 12$ & & $\begin{array}{l}\text { Momet Maymó } \\
\text { Nassan Salamó } \\
\text { Samuel Benvenist } \\
\text { Nassan Salamó }\end{array}$ & fisic & $61 \mathrm{v}$ \\
\hline $1391 / 03 / 15$ & & $\begin{array}{l}\text { Caravida Gracia, pare } \\
\text { Lobell Gracià, fill } \\
\text { Abram Sescaleta } \\
\text { Abraham Pontardia }\end{array}$ & corredor & $62 \mathrm{r}$ \\
\hline $1391 / 03 / 16$ & & $\begin{array}{l}\text { Abraham Sescaleta } \\
\text { Caravida Gracià, pare } \\
\text { Lobell Gracià, fill } \\
\text { Bonjuha Struch }\end{array}$ & $\begin{array}{l}\text { Corredor } \\
\text { teixidor vels }\end{array}$ & $62 \mathrm{v}$ \\
\hline $1391 / 03 / 30$ & & $\begin{array}{l}\text { Salomo Atzara } \\
\text { Vidal Ferrer }\end{array}$ & & $66 r$ \\
\hline $1391 / 04 / 17$ & & $\begin{array}{l}\text { Dolcich, muller de } \\
\text { Struch Perfet, } q^{\circ} \text {, a } \\
\text { Salamó Vidal Scaleta i } \\
\text { Vidal Ferrer } \\
\text { Bonafilia, filla de Dolcich } \\
\text { Boinafós Bonmacip, fill de } \\
\text { Bonmacip Struch } \\
\text { Juceff de Ripoll } \\
\end{array}$ & & $75 r$ \\
\hline
\end{tabular}




\begin{tabular}{|c|c|c|c|c|}
\hline $1391 / 04 / 18$ & & $\begin{array}{l}\text { Issach Mosse } \\
\text { Abraham Pijó, marit de } \\
\text { Siti, muller } \\
\text { Benvenguda, muller de } \\
\text { Mosse Pijó, } \mathrm{q}^{\circ} \text {, marit } \\
\text { Abram Aron }\end{array}$ & $\begin{array}{l}\text { sastre } \\
\text { sastre } \\
\text { assahonador } \\
\text { sastre }\end{array}$ & $75 \mathrm{~V}$ \\
\hline $1391 / 04 / 19$ & & $\begin{array}{l}\text { Struch Febib } \\
\text { Barzelay Fabib } \\
\text { Davi Merçana } \\
\text { Sotalam Caravida, mestre }\end{array}$ & $\begin{array}{l}\text { paraire draps } \\
\text { teixidor vels } \\
\text { teixidor vels }\end{array}$ & $75 \mathrm{v}$ \\
\hline $1391 / 04 / 19$ & & $\begin{array}{l}\text { Regino, muller } \\
\text { Issach Salamó de Caules, marit }\end{array}$ & seder & $78 \mathrm{r}$ \\
\hline $1391 / 04 / 19$ & & $\begin{array}{l}\text { Juceff Bonatos } \\
\text { Juceff ça Porta } \\
\text { Juceff Enangena }\end{array}$ & & $81 \mathrm{r}$ \\
\hline $1391 / 05 / 08$ & & $\begin{array}{l}\text { Salamo Abram, pare } \\
\text { Abram Salamó, fill }\end{array}$ & coraler & 8Ir \\
\hline 1391/05/08 & & $\begin{array}{l}\text { Bonanasch Struch } \\
\text { Vives Struch }\end{array}$ & & $82 \mathrm{r}$ \\
\hline $1391 / 06 / 09$ & & $\begin{array}{l}\text { Vidal Jafia } \\
\text { Issach Vides } \\
\text { Struch Manatre }\end{array}$ & $\begin{array}{l}\text { coraler } \\
\text { coraler }\end{array}$ & $90 \mathrm{v}$ \\
\hline $1391 / 06 / 18$ & & $\begin{array}{l}\text { Davi de Bellcalre } \\
\text { Salamó sa Torra }\end{array}$ & & प94 \\
\hline $1391 / 06 / 29$ & & $\begin{array}{l}\text { Struch Manacem } \\
\text { Atzarch Adret } \\
\text { Maymó de Campredó }\end{array}$ & $\begin{array}{l}\text { mestre coral } \\
\text { mestre coral }\end{array}$ & $\overline{9} / \mathrm{v}$ \\
\hline $1391 / 06 / 30$ & & $\begin{array}{l}\text { Struch Bonanasch, pare } \\
\text { Bonanasch Struc, fill } \\
\text { Juceff Issach de Puntardia }\end{array}$ & & $97 \mathrm{v}$ \\
\hline $1391 / 07 / 28$ & & $\begin{array}{l}\text { Samuel Benvenist Major } \\
\text { Salamó Melado }\end{array}$ & & $104 \mathrm{v}$ \\
\hline $1391 / 08 / 22$ & $\begin{array}{l}\text { Parer, Francesc, } 16 \text { a. } \\
\text { Vilamarí, Francesc }\end{array}$ & $=$ Issach Badorch & $\begin{array}{l}\text { teixidor vels } \\
\text { teixidor vels }\end{array}$ & $109 \mathrm{v}$ \\
\hline $1391 / 08 / 22$ & $\begin{array}{l}\text { Calat, Bernat, espos } \\
\text { Joana, esposa } \\
\text { Casasagia, Francesc de }\end{array}$ & = Bonjach Comprat & $\begin{array}{l}\text { Juponer } \\
\text { sastre }\end{array}$ & $109 \mathrm{~V}$ \\
\hline 1391/10/06 & Prades, Pere de & = Caravida Gracia & corredor & $118 \mathrm{r}$ \\
\hline $1391 / 10 / 17$ & $\begin{array}{l}\text { Vidal, Joan, germans } \\
\text { Déus, Domènech ses }\end{array}$ & = Juceff sa Porta & $\begin{array}{l}\text { telxidor vels } \\
\text { coraler }\end{array}$ & TIIr \\
\hline $1391 / 10 / 27$ & Pla, Pere de & & & I22V \\
\hline $1391 / 10 / 28$ & $\begin{array}{l}\text { Esteve, Joan, marit } \\
\text { Joaneta, muller } \\
\text { Pujada, Jaume } \\
\text { Déus, Domènech ses }\end{array}$ & & $\begin{array}{l}\text { coraler } \\
\text { corredor orella } \\
\text { coraler }\end{array}$ & T23r \\
\hline $1391 / 10 / 28$ & $\begin{array}{l}\text { Clots, Francesc de, espos } \\
\text { Elionor, esposa, filla de } \\
\text { Crivell, Jaume } \\
\text { Déus, Domènech ses } \\
\text { Serra, Pere }\end{array}$ & $=$ Mosse Nassan & $\begin{array}{l}\text { teixidor vels } \\
\text { coraler } \\
\text { torner }\end{array}$ & $123 \mathrm{v}$ \\
\hline 1391/11/10 & Thanuel, Jaume & = Salamo Caravida & mestre medicina & $12 / \mathrm{r}$ \\
\hline $1391 / 11 / 10$ & Queralt, Donat de, nebot de & Struch Bondavi des Cortal, oncle & & $127 \mathrm{v}$ \\
\hline 1391/11/21 & $\begin{array}{l}\text { Guich, Francesc } \\
\text { Casasagia, Francesc de }\end{array}$ & $\begin{array}{l}=\text { Salamo Atzara } \\
=\text { Bonjach Comprat }\end{array}$ & sastre & T3Iv \\
\hline $1391 / 11 / 21$ & Gibert, Francesc & $=$ Vives Bonjach & teixidor vels & I32v \\
\hline $1391 / 11 / 24$ & $\begin{array}{l}\text { Ferrer, Domenec } \\
\text { Cassasagia, Francesc de } \\
\text { Ripoll, Pere } \\
\text { Montalta, Bernat }\end{array}$ & $\begin{array}{l}=\text { Juceff Abeff } \\
=\text { Bonjach Comprat }\end{array}$ & $\begin{array}{l}\text { mercader } \\
\text { sastre } \\
\text { llibreter }\end{array}$ & T32v \\
\hline $1391 / 11 / 29$ & $\begin{array}{l}\text { Francesca, muller de Sala- } \\
\text { mó Cescaleta } \\
\text { Joanet, fill } \\
\text { Aganasona, filla }\end{array}$ & $\begin{array}{l}\text { Salamó Vidal Sescaleta, } q^{\circ} \text {, marit } \\
\text { de Francesca }\end{array}$ & & $134 \mathrm{r}$ \\
\hline $1391 / 11 / 29$ & Aragay, Pere & $=$ Bonanasch Struch & & $134 \mathrm{r}$ \\
\hline $1391 / 12 / 08$ & Aragay, Pere & $=$ Bonanasch Struch & & $13 / \mathrm{r}$ \\
\hline $1391 / 12 / 16$ & Pou, Pere de & & sastre & $138 \mathrm{r}$ \\
\hline $1391 / 12 / 26$ & $\begin{array}{l}\text { Caterına, esposa } \\
\text { Cortey, Joan, espòs } \\
\text { Sescala, Joan Ramon } \\
\text { Fortià, Bernat de }\end{array}$ & $\begin{array}{l}\text { fllla de salvat Françes, q, i de } \\
\text { Mariam, muller, } \mathrm{q}^{\circ} \\
\text { fill de Sentou Petit, } \mathrm{q}^{\circ} \text {, i de } \\
\text { Bonadona, } \mathrm{q}^{\circ}\end{array}$ & $\begin{array}{l}\text { torner } \\
\text { torner } \\
\text { sastre }\end{array}$ & $140 \mathrm{r}$ \\
\hline $1391 / 12 / 26$ & $\begin{array}{l}\text { Sescales, Ramon } \\
\text { Mulet, Guillem } \\
\text { Sansa, Joan de }\end{array}$ & = Jaffiel Ferrer & & T40V \\
\hline
\end{tabular}




\begin{tabular}{|c|c|c|c|c|}
\hline $1392 / 01 / 06$ & $\begin{array}{l}\text { Fizı, Lleonard, espos } \\
\text { Constança, esposa }\end{array}$ & $\begin{array}{l}\text { fill de }[. .] 1 \text { de } \\
\text { Mariam }\end{array}$ & mestre de daus & $142 \mathrm{v}$ \\
\hline $1392 / 01 / 08$ & $\begin{array}{l}\text { Ulzina, Antoni } \\
\text { Maria } \\
\text { Pont, Joan de } \\
\text { Conomines, Bernat de } \\
\text { Pou, Pere de }\end{array}$ & $\begin{array}{l}\text { = Issach lacob } \\
=\text { Mariam, uxor } \\
\text { germà de Maria }\end{array}$ & $\begin{array}{l}\text { mestre cortines } \\
\text { porter del rei } \\
\text { sastre } \\
\text { sastre }\end{array}$ & $143 \mathrm{r}$ \\
\hline
\end{tabular}

El signe = indica que el nom que segueix correspon al nom jueu abans de la conversió. Abreviatures: $q^{\circ}$ (quondam) = difunt; $r$ =recte; $v$ = vers.

\title{
2. Registres dels ordenats
}

\author{
REGISTRA ORDINATORUM
}

ADC, vols. 7, 8, 9, 10

\begin{tabular}{|c|c|c|c|c|}
\hline DATA & CUNVERS-IUNSURAT & LLUC DURIGEN & PARE & OFICI-PARE \\
\hline $1392 / 09 / 11$ & Alamany, Bernardus & & & \\
\hline $1393 / 04 / 05$ & Gibert, Franciscus & ville Apiarie, dB & & \\
\hline $1395 / 06 / 05$ & Vall, lohannes, al. Lança & Barcelona & Lança, Bertrandus & \\
\hline $1396 / 03 / 18$ & Serra, Gabriel & Barcelona & Serra, Gabriel & \\
\hline $1399 / 03 / 15$ & Badia, Arnaldus & Barcelona & $\begin{array}{l}\text { Badia, Bartholomeus } \\
=\text { Abram Bandil }\end{array}$ & payerius \\
\hline $1399 / 03 / 15$ & Goçeti, Macıanus & Barcelona & Goçetı, Guillermus & sartor \\
\hline $1399 / 05 / 24$ & Quintana, Petrus & $\begin{array}{l}\text { Olesa de Montserrat, } \\
\text { dB }\end{array}$ & Quintana, Vincentius & \\
\hline $1399 / 09 / 20$ & Guimera, Iohannes & Molins de Rei, dB & Guimera, Bernardus & \\
\hline $1401 / 04 / 10$ & Ferrandi, Gabriel & Barcelona & Ferrando, Garcia & \\
\hline $1402 / 09 / 13$ & Garrigua, Antonius & Barcelona & $\begin{array}{l}\text { Garriga, Guillermus } \\
=\text { Salomó Fabila }\end{array}$ & torner \\
\hline $1403 / 06 / 09$ & Merles, Ferrarius & Barcelona & Merles, Petrus & \\
\hline $1403 / 09 / 22$ & Ferraril, Genesius & Barcelona & Ferreril, Genesius & curritoris auri \\
\hline $1404 / 11 / 10$ & Closa, Michael sa & Barcelona & Closa, Bernardus sa & \\
\hline $1404 / 12 / 20$ & Pedralbis, Nicholaus de & Barcelona & Pedralbis, Franciscus de & phisicus \\
\hline $1405 / 03 / 14$ & Podiolo, Franciscus de & Barcelona & Podrolo, Petrus de & fisicus \\
\hline $1405 / 05 / 10$ & Gualbes, Ferrarıus de & Barcelona & $\begin{array}{l}\text { Gualbis, Ferrarlus de = Issach } \\
\text { Bonsenyor Gracia }\end{array}$ & \\
\hline $1407 / 04 / 00$ & Roger, Andreas & Barcelona & Rogeril, Arnaldus & Curritor auris \\
\hline $1407 / 05 / 21$ & Pratis, Ferrarius de & Barcelona & Pratis, Gabriel de & cederius \\
\hline $1407 / 12 / 19$ & Bertrandi, lohannes & Barcelona & $\begin{array}{l}\text { Bertrandi, Iohannes } \\
=\text { Samuel Benvenist }\end{array}$ & curritor auricole \\
\hline $1408 / 03 / 08$ & Plangual, Ferrarıus de & Barcelona & Plangual, Nicolaus de & \\
\hline $1409 / 06 / 02$ & Rich, Gabriel & Barcelona & Rich, Gabriel & curritor auris \\
\hline $1410 / 12 / 20$ & Rosar, Gabriel & Barcelona & Rosar, Anthonius & \\
\hline $1410 / 12 / 20$ & Morles, Gabriel & Barcelona & Merles, Petrus & \\
\hline $1410 / 12 / 20$ & Sant Johan, Bonanatus & Barcelona & Sant Johan, Iohanne & \\
\hline $1412 / 04 / 05$ & Pedralbis, Iohannes de & Barcelona & Pedralbis, Franciscus de & $\begin{array}{l}\text { Ticencratus in } \\
\text { medecina }\end{array}$ \\
\hline $1413 / 03 / 12$ & Queralt, Gabriel de & Barcelona & & \\
\hline $1416 / 03 / 77$ & Salmons, Marchus & Barcelona & Salmons, Marchus & sederius \\
\hline $1416 / 04 / 04$ & Salmons, Ludovicus & Barcelona & Salmons, Marchus & sederius \\
\hline $1417 / 05 / 23$ & Vilella, Franciscus & Barcelona & Vilella, Iohannes & tincturarius \\
\hline $1417 / 06 / 12$ & Cavalleria, Bernardus de la & $\begin{array}{l}\text { Scolarıs, neophitus, } \\
\text { civitatis Cesaraugus- } \\
\text { te oriundus }\end{array}$ & & \\
\hline $1417 / 06 / 29$ & Badia, Gabriel & Barcelona & Badia, Petrus $=$ Issach Vidal & coralerius \\
\hline $1418 / 03 / 12$ & Rosar, Petrus & Barcelona & Rosar, Anthonius & juponerius \\
\hline $1418 / 05 / 21$ & Solsona, Rafael & Barcelona & Solsona, Iohannes & juponerius \\
\hline $1418 / 05 / 21$ & Fontclara, Manuel de & Barcelona & Fontclara, Gullelmus de & curritor auris \\
\hline $1419 / 01 / 00$ & Gualbis, lacobus de & Barcelona & $\begin{array}{l}\text { Gualbes, Ludovicus = Daviu } \\
\text { Jaques }\end{array}$ & \\
\hline $1420 / 03 / 02$ & Far, Iohannes dez & Barcelona & Far, lohannes dez & payerius \\
\hline $1421 / 04 / 06$ & Quer, Philippus dez & Barcelona & Badorch dez Quer, Berengarius & payerius \\
\hline $1420 / 04 / 30$ & Casasaia, Franciscus de & Barcelona, scolaris & $\begin{array}{l}\text { Casasaia, Franciscus de = Bon- } \\
\text { jach Comprat }\end{array}$ & mercator \\
\hline $1422 / 12 / 26$ & Massana, Petrus & Barcelona & Massana, Gabriel & curritor auris \\
\hline $1423 / 02 / 06$ & Sanxo, Nicholaus & Barcelona & Sanxo, Guillelmus & mercatoris \\
\hline $1425 / 12 / 02$ & Coma, Guillermus & Barcelona & Coma, Guillermus & Tibraterius \\
\hline $1427 / 04 / 19$ & Benedicti, Petrus & Neophitus B & & \\
\hline $1427 / 05 / 04$ & Pedralbes, Franciscus de & scolaris B & Pedralbes, Franciscus de & $\begin{array}{l}\text { magister in me- } \\
\text { dicina }\end{array}$ \\
\hline $1428 / 12 / 18$ & Civeller, Francischus & Barcelona & Civeller, Gullermus & curritor botigie \\
\hline
\end{tabular}




\begin{tabular}{|c|c|c|c|c|}
\hline $1431 / 05 / 06$ & Sabater, Bernardus & Barcelona & Sabater, Salvator & tibraterıus \\
\hline $1431 / 06 / 02$ & Sanxo, Gabriel & Barcelona & Sanxo, Guillelmus & mercator \\
\hline $1432 / 12 / 20$ & Rosar, Philipus & Barcelona & Rosar, Anthonius & juponerius \\
\hline $1433 / 09 / 18$ & $\begin{array}{l}\text { Pedralbes, lohannes } \\
\text { v. } 1412 / 04 / 05: \text { tonsura }\end{array}$ & $\begin{array}{l}\text { Barcelona - demana } \\
\text { dimissòries }\end{array}$ & Pedralbes, Franciscus de & $\begin{array}{l}\text { magister in me- } \\
\text { dicina }\end{array}$ \\
\hline $1433 / 12 / 20$ & Ferreres, Bernardus de & Barcelona & $\begin{array}{l}\text { Ferreres, Guillem = } \\
\text { Issach Struch }\end{array}$ & coralerıus \\
\hline $1434 / 06 / 11$ & Vallsecha, Iohannes de & Barcelona & Vallsecha, Petrus de & de domo regis \\
\hline $1436 / 04 / 07$ & Ballistaril, Petrus & Barcelona & $\begin{array}{l}\text { Ballistaril, Raymun-dus = Sa- } \\
\text { muel Alietzer }\end{array}$ & textor velorum \\
\hline $1436 / 06 / 06$ & Costa, Laurentius & Barcelona & Costa, Laurentius & Iibraterius \\
\hline $1438 / 12 / 26$ & Castell, Ionannes & Barcelona & Castell, Simon & textor velorum \\
\hline $1438 / 12 / 26$ & Sunyer, Iohannes & Barcelona & Simon, Francischus & curritor auris \\
\hline $1439 / 01 / 04$ & Mascharo, Guillelmus & Barcelona & $\begin{array}{l}\text { Mascharo, Petrus } \\
\text { avus: Mahir Bonjuha }\end{array}$ & $\begin{array}{l}\text { Tibraterius } \\
\text { ligator librorum }\end{array}$ \\
\hline $1439 / 01 / 04$ & Mascharo, Petrus & Barcelona & $\begin{array}{l}\text { Mascharo, Petrus } \\
\text { avus: Mahir Bonjuha }\end{array}$ & $\begin{array}{l}\text { Tibraterius } \\
\text { ligator librorum }\end{array}$ \\
\hline $1439 / 03 / 01$ & Ferrer, Laurentius & Barcelona & Ferrer, Francischius & curritor auris \\
\hline $1440 / 04 / 03$ & Pedralbes, Nicholaus & Barcelona & Pedralbes, Francischus de & $\begin{array}{l}\text { professor in } \\
\text { medicina }\end{array}$ \\
\hline $1442 / 01 / 06$ & Raymundi, lohannes & Barcelona & Raymundi, Anthonius & Tibraterius \\
\hline $1442 / 03 / 07$ & Cavalleria, Philippus de la & Barcelona & Cavalleria, Philippus de la & mercator \\
\hline
\end{tabular}

El signe = indica que el nom que segueix correspon al nom jueu abans de la conversió Abreviatures: $\mathrm{B}$ = Barchinone o Barcelona; $\mathrm{dB}=$ diòcesi de Barcelona. 


\title{
APÈNDIX D’ARBRES GENEALÒGICS
}

\section{Familia de Bonsenyor Gracià}

\author{
Bonsenyor Gracià, jueu, pare

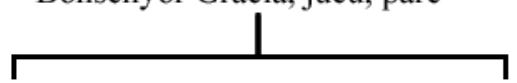 \\ Issach Bonsenyor Gracià, fill Mosse Bonsenyor Gracià, jueu, fill \\ $=$ Ferrer de Gualbes, convers
}

2. Familia de Bonjuha Bonsenyor i de Davi Aron

\author{
Bonjuha Bonsenyor \\ $=$ Lleonard Ferrer, convers, pare \\ I
}

Vidal Bonjuha, jueu, fill

Dolça --_-_-_-_-_-_-- Davi Aron, jueu marit

$=$ Vidala, conversa, muller

3. Familia de Benvenist Samuel

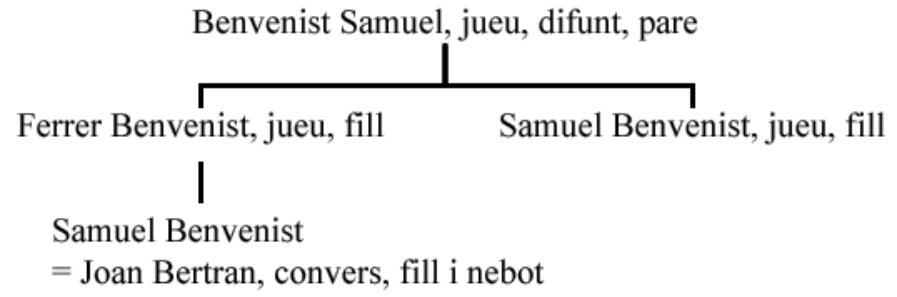




\section{Família de Vidal Belshom}

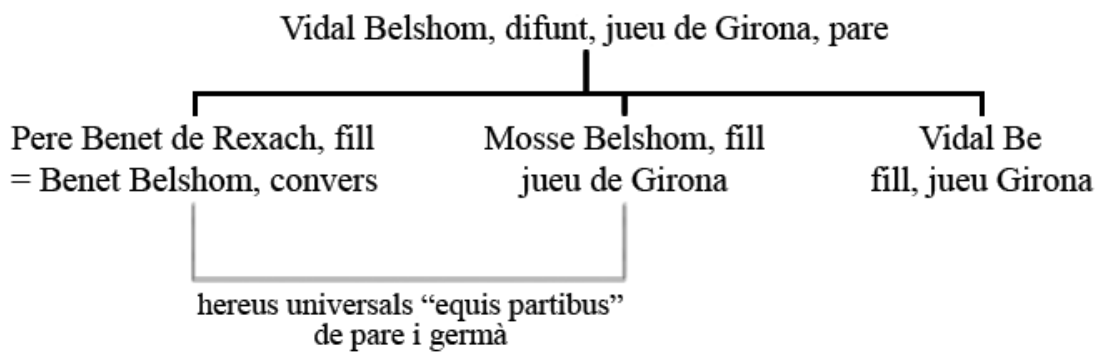

5. Família de Juceff de Beses i Berenguer de Cortil

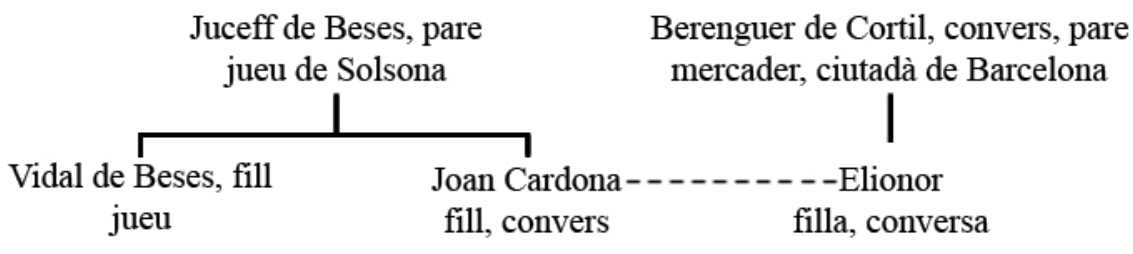

6. Família d'Astruch Bendit

Astruch Bendit, difunt, jueu de Solsona, pare

$\begin{array}{cc}\begin{array}{c}\text { Cresques Bendit, fill } \\ \text { jueu de Solsona }\end{array} & \begin{array}{c}\text { Guillem Fivaller, fill, convers } \\ \text { corredor d'orella } \\ \text { ciutada de Barcelona }\end{array}\end{array}$


7. Ruptura del matrimoni de Caterina i Pere de Pla.

Família d'Isaach Ferrer

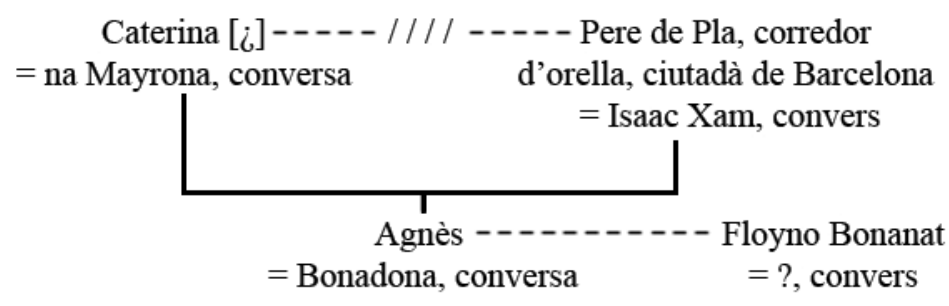

Caterina [i] - - - - - //// - - - - - Pere de Pla, corredor = na Mayrona, conversa d'orella, ciutadà de Barcelona

Agnès --- ------ Floyno Bonanat

$=$ Bonadona, conversa $\quad=$ ?, convers

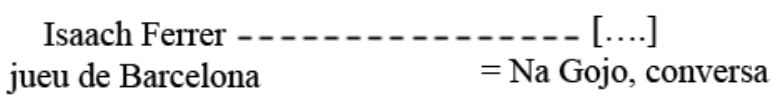

\section{Família de Francesc Bertran}

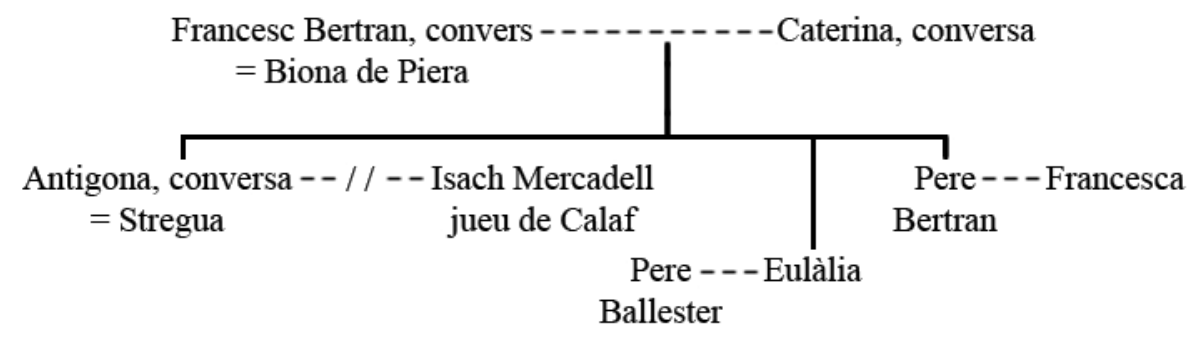

9. Família de Francesc Ros i Isaach Torquós

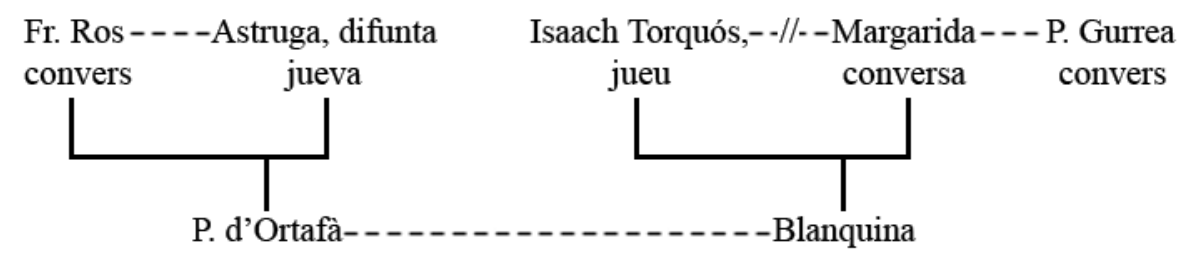




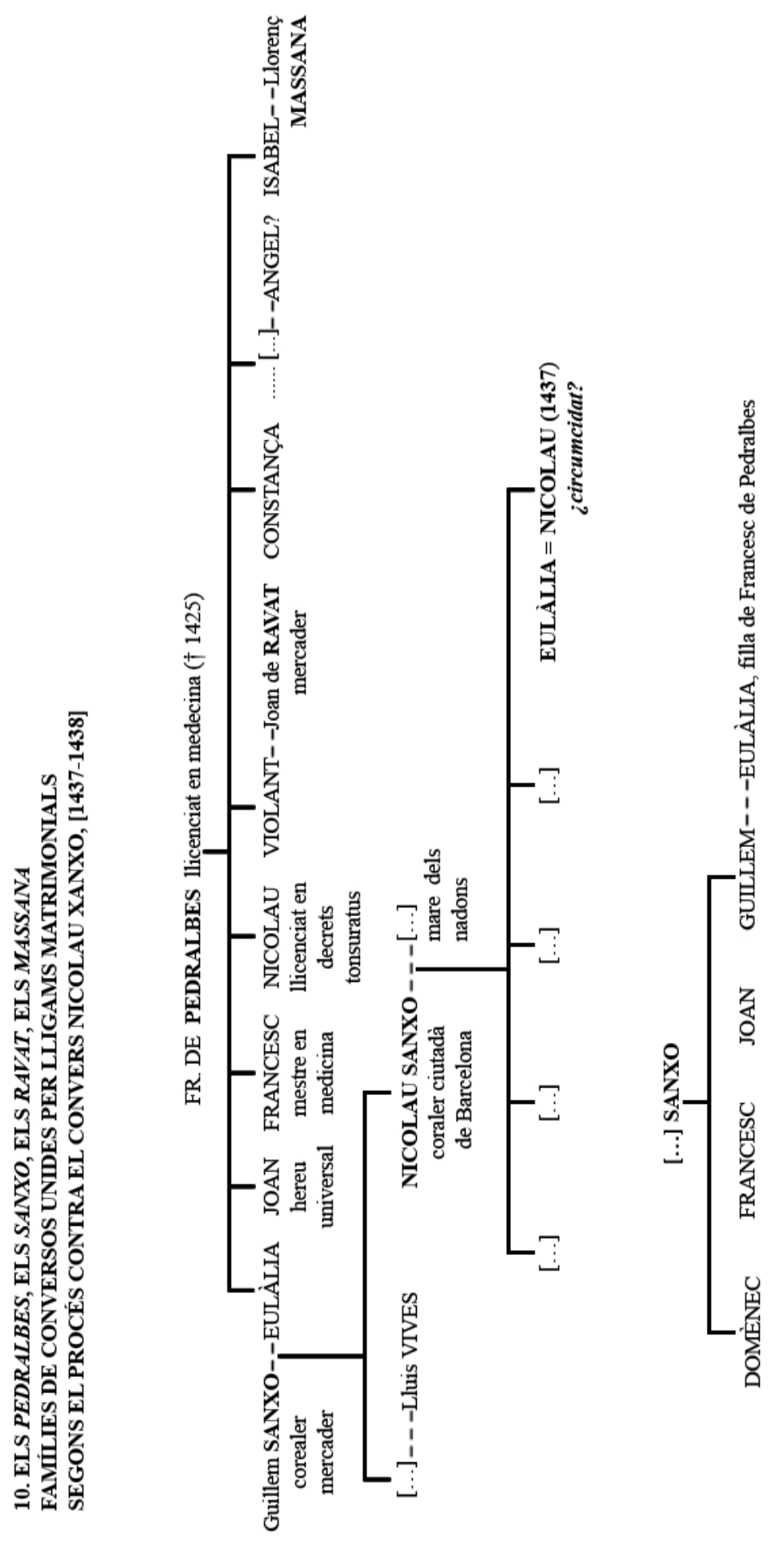




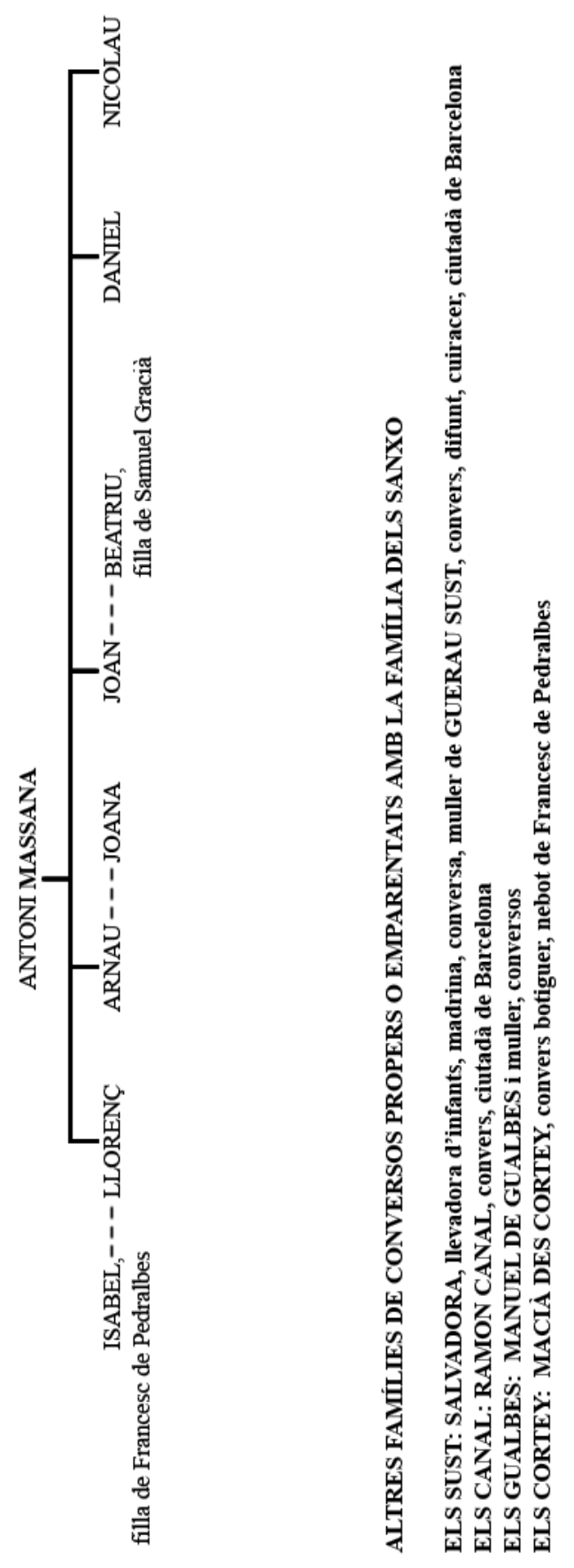

